\title{
REVISÃO TAXONÔMICA E RELAÇÕES FILOGENÉTICAS DAS ESPÉCIES DE ROEBOIDES GRUPO-MICROLEPIS (OSTARIOPHYSI, CHARACIFORMES, CHARACIDAE)
}

\author{
Carlos Alberto Santos Lucena ${ }^{1}$
}

\begin{abstract}
TAXONOMIC REVISION AND PHYLOGENETIC RELATIONSHIPS OF THE ROEBOIDES MICROLEPIS SPECIES-GROUP (OSTARIOPHYSI, CHARACIFORMES, CHARACIDAE). The Roeboides microlepis species-group is revised. Four species are recognized: R. myersii Gill, 1870 from the Amazon basin, R. microlepis (Reinhardt, 1851) from river Paraguay, middle and lower river Paraná, $R$. araguaito sp. nov. from the river Orinoco basin, and $R$. margareteae sp. nov. known only from Rio Parnaíba and Pindaré-Mearim, northeastern Brazil. The type-locality of $R$. microlepis is restricted to river Paraguay; $R$. bonariensis (Steindachner, 1879) is considered a synonym of $R$. microlepis. The phylogenetic analysis indicates that $R$. myersii and $R$. araguaito are most parsimoniously related and may be a sister group. These two species are here considered as sister group of the monophyletic lineage which includes $R$. microlepis and $R$. margareteae. A key to the microlepis species-group genus Roeboides is given.
\end{abstract}

KEYWORDS. Fishes, Neotropical, taxonomy, Roeboides, phylogeny.

\section{INTRODUÇÃO}

A definição do gênero Roeboides Günther, 1864 e suas possíveis relações (LuCENA, 1998), a revisão e filogenia dos grupos monofiléticos internos (LuCENA, 2000a, 2001) e descrições de novas espécies (LuCENA, 2000b) já foram apresentadas. Dois grupos monofiléticos internos do gênero ainda não foram investigados, o grupo-microlepis (subclado B em LuCENA, 1998) e o grupo-affinis (subclado C em Lucena, 1998).

As espécies do grupo-microlepis formam um grupo monofilético por compartilharem de um elevado número de escamas perfuradas na linha lateral (mais de 88 ), presença de 7 a 10 fileiras de escamas que formam uma bainha em quase toda extensão da base da nadadeira anal e limite anterior da abertura entre os ramos posteriores do paresfenóide estar localizado bem à frente da vertical que passa pelo limite dos ossos basioccipital e pró-ótico (LuCENA, 1988, 2000a). Segundo a hipótese de LuCENA (2000a: fig. 1) o grupomicrolepis é mais relacionado às espécies transandinas, grupo-guatemalensis (subclado D em LuCEnA, 1998), do que os demais grupos internos do gênero Roeboides. O grupo-

1. Laboratório de Ictiologia, Museu de Ciências e Tecnologia, Pontifícia Universidade Católica do Rio Grande do Sul, Av. Ipiranga 6681, prédio 40, 90619-900, Porto Alegre, RS, Brasil. lucena@pucrs.br 
microlepis é formado por três espécies: $R$. microlepis (Reinhardt, 1851), espécie-tipo do gênero, R. myersii Gill, 1870 das drenagens dos rios Amazonas e Orinoco e R. bonariensis (Steindachner, 1879) da drenagem do rio Paraguai, e do médio e baixo rio Paraná. Objetiva-se revisar a taxonomia das espécies do grupo-microlepis e propor suas relações internas em Roeboides.

\section{MATERIAL E MÉTODOS}

As seguintes instituições forneceram material para estudo: Academy of Natural Sciences, Philadelphia (ANSP); Museo de Biologia, Universidad Central de Venezuela, Caracas (MUCV); Museu de Ciências e Tecnologia, Pontifícia Universidade Católica do Rio Grande do Sul, Porto Alegre (MCP); Museum of Comparative Zoology, Cambridge (MCZ); Museo Nacional de Historia Natural del Paraguay, Assunção (MHNP); Muséum National d'Histoire Naturelle, Paris (MNHN); Museu de Zoologia, Universidade de São Paulo, São Paulo (MZSP); Swedish Museum of Natural History, Estocolmo (NRM); Museum of Zoology, University of Michigan, Ann Arbor (UMMZ); Universidade Federal do Piauí, Teresina (UFPI); National Museum of Natural History, Smithsonian Institution, Washington, D.C. (USNM).

A análise filogenética segue os procedimentos expressos em HenNIG (1966) e artigos posteriores (Wiley, 1981; Forey et al. 1992). A hipótese de Lucena (1998, 2000a), quanto às relações de Roeboides, foram utilizadas como base para o estabelecimento dos grupos externos. Essa hipótese considera que o grupo-guatemalensis + o grupo-microlepis formam clados-irmãos, com os demais grupos, grupoaffins e grupo-dispar (esse último tratado como subclado A em LuCENA, 1998) constituindo-se em clados mais inclusivos. As espécies Roeboides dientonito Schultz, 1944, R. affinis (Günther, 1864) e $R$. dispar Lucena, 2001, representaram, na presente análise, os grupos citados. Essas espécies, mais o gênero Charax Scopoli, 1777 representado por C. gibbosus (Linnaeus, 1758), compuseram o grupo-externo. Todas foram reunidas em um único grupo-externo hipotético. A utilização do sinal “?" na matriz ocorreu devido à variação do caráter no táxon examinado ou quando houve conflito entre os estados do caráter, impossibilitando a proposição do estado plesiomórfico. O método proposto por MADDISON et al., 1984 foi usado para o estabelecimento do estado presente no grupo-externo.

$\mathrm{Na}$ construção da árvore mais parcimoniosa e o acompanhamento da transformação dos caracteres foi utilizado o programa Hennig 86 associado ao TreeGardner 2.2. O algoritmo ie* foi o escolhido. Não foram atribuídos pesos aos caracteres e os caracteres multiestados foram tratados como não-ordenados. A ordem dos caracteres na matriz (tab. I) é a mesma da lista dos caracteres.

As medidas e contagens foram feitas segundo Fink \& Weitzman (1974) e Menezes \& Lucena (1998). Os exemplares utilizados para observações das estruturas ósseas foram preparados de acordo com a técnica de Dingerkus \& Uhler (1977). A contagem das vértebras inclui as quatro do complexo de Weber e a vértebra que sustenta o complexo uróforo. A análise dos dados merísticos e morfométricos apresentados nas tabelas, foi feita com o programa Datax. Os testes estatísticos foram feitos através do programa SigmaStat for Windows 95. No material examinado após o número de catálogo, entre parênteses, é fornecido o número de exemplares do lote seguido do menor e maior comprimento padrão $(\mathrm{mm})$.

As sinonímias restringem-se às descrições originais, mudanças de gênero e/ou novas sinonímias. Abreviaturas usadas: $\mathrm{CP}$, comprimento padrão; dc, diafanizado e corado. O material comparativo adicional utilizado na osteologia está listado em Lucena (1998) e Lucena \& Menezes (1998).

\section{RESULTADOS}

\section{Lista dos caracteres:}

1. Rinoesfenóide. (0) Ausente. (1) Presente.

2. Paresfenóide. (0) Em contato, ou fusionado, com o órbito-esfenóide. (1) Distante do órbito-esfenóide.

3. Larga bainha de escamas ao longo da base da nadadeira anal. (0) Ausente. (1) Presente.

4. Extensão do processo transversal da terceira vértebra do aparelho de Weber. (0) Longo. (1) Curto. 
5. Projeção mediana do órbito-esfenóide. (0) Reto ou levemente côncavo na região ânterosuperior, sem formar elevação. (1) Com uma elevação em ponta curva na região ântero-superior.

6. Número total de vértebras. (0) 38 ou menos. (1) 39.

7. Primeiro espinho hemal. (0) Com porção distal afilada. (1) Com porção distal alargada.

8. Número de escamas perfuradas da linha lateral. (0) De 93 a 106 escamas (média=96,7). (1) De 86 a 99 escamas (média=91,2). (2) De 51 a 89 escamas.

9. Base do processo neural especializado, próximo ao uróstilo. (0) Com a presença de um poro conspícuo. (1) Com dois, algumas vezes três, poros conspícuos.

10. Infra-orbital 4. (0) Presente. (1) Ausente (ver LuCENA, 1998 para detalhes).

11. Número de pterigióforos à frente do primeiro espinho hemal. (0) 8 ou 9. (1) 6 ou 7.

12. Forame do nervo troclear. (0) Formado, principalmente, pelo pteroesfenóide. (1) Formado, igualmente, pelos ossos pteroesfenóide e órbito-esfenóide, ou somente pelo pteroesfenóide.

13. Região dorsal do retroarticular. (0) Com sua maior extensão localizada atrás da vertical que passa posterior à base do côndilo do quadrado. (1) Com sua maior extensão localizada sob a base do côndilo do quadrado.

14. Ângulo-articular. (0) Com sua região posterior ao local onde articula-se o côndilo do quadrado, afilada e estendendo-se bem além da vertical que passa pela margem posterior do retroarticular. (1) Com sua região posterior ao local onde articula-se o côndilo do quadrado, larga e estendendo-se pouco além da vertical que passa pela margem posterior do retroarticular.

15. Projeção mediana do órbito-esfenóide. (0) Com sua porção ínfero-anterior arredondada. (1) Com sua porção ínfero-anterior com ponta aguda dirigida para baixo e para frente.

Tabela I. Matriz de caracteres das espécies de Roeboides grupo-microlepis e grupo-externo.

\begin{tabular}{llllllllllllllll}
\hline Táxons/Caracteres & 1 & 2 & 3 & 4 & 5 & 6 & 7 & 8 & 9 & 1 & 1 & 1 & 1 & 1 & 1 \\
& & & & & & & & & & 0 & 1 & 2 & 3 & 4 & 5 \\
\hline$R$. araguaito & 0 & 0 & 1 & 0 & 1 & 0 & 1 & 1 & 0 & 1 & 1 & 1 & 1 & 0 & 0 \\
R. margareteae & 0 & 0 & 1 & 1 & 0 & 1 & 0 & 0 & 0 & 0 & 0 & 0 & 1 & 0 & 1 \\
$R$. microlepis & 0 & 0 & 1 & 1 & 0 & 0 & 0 & 0 & 0 & 1 & 0 & 0 & 0 & 1 & 1 \\
$R$. myersii & 0 & 0 & 1 & 0 & 0 & 0 & 0 & 1 & 1 & 1 & 0 & 1 & 0 & 1 & 0 \\
Grupo-externo & 1 & 1 & 0 & 1 & 0 & 0 & 0 & 2 & 0 & $?$ & 0 & $?$ & 1 & $?$ & 0 \\
\hline
\end{tabular}

A análise filogenética indicou uma única árvore de maior parcimônia na hipótese de relações internas do grupo-microlepis, com 12 passos de comprimento, índice de consistência 0,81 e índice de retenção 0,60 (fig. 1). A seguir são apresentadas as sinapomorfias resultantes da análise que definem o grupo-microlepis e clados internos. Os números, entre parênteses, após a sinapomorfia, indicam o caráter e o respectivo estado e são os mesmos citados na lista de caracteres.

A análise indicou ainda, duas sinapomorfias adicionais, não exclusivas, para o grupo-microlepis: ausência do rinoesfenóide (1.0) e presença de contato, ou fusão, entre o órbito-esfenóide e o paresfenóide (2.0). Ambas, junto à presença de uma larga bainha de escamas na base da nadadeira anal (3.1), do número de escamas da linha lateral 

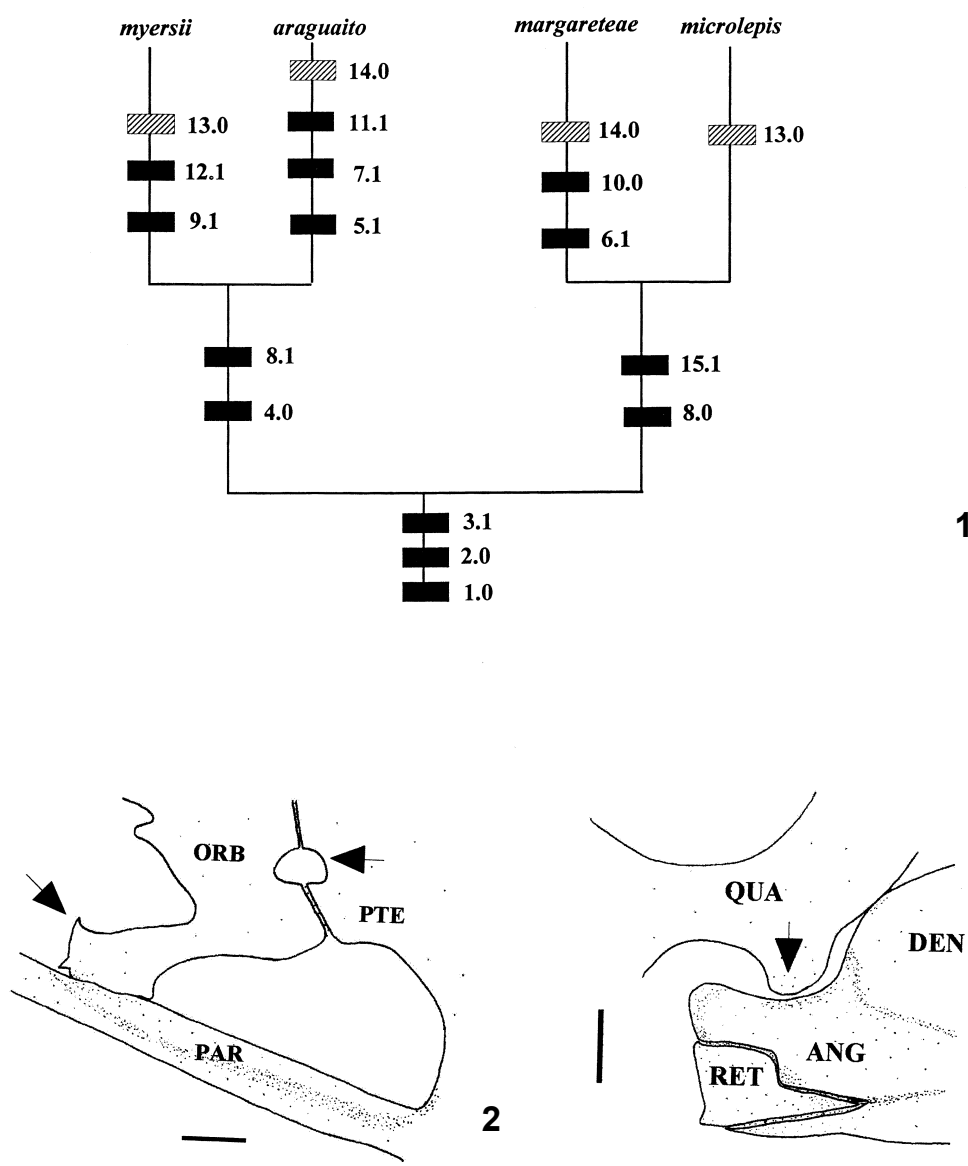

Figs. 1-3. 1, Cladograma com a hipótese de maior parcimônia das relações interespecíficas de Roeboides grupo-microlepis (caracteres homoplásticos associados aos retângulos barrados e caracteres únicos e não-ambíguos aos retângulos escuros). 2, Vista medial de parte do crânio de Roeboides araguaito, USNM 181353 (seta superior, forame troclear, caráter 12.0; seta inferior, região do órbito-esfenóide com pontas, caracteres 5.1 e 15.1). 3, Vista medial de parte da maxila inferior esquerda e arco mandibular de Roeboides myersii, MZSP não numerado, caracteres 13.0 e 14.1 (seta indica o côndilo do quadrado). Barra, 1mm. ANG, ângulo-articular; DEN, dentário; ORB, órbito-esfenóide; PAR, paresfenóide; PTE, pteroesfenóide; QUA, quadrado; RET, retroarticular.

e da posição do limite anterior da abertura que há entre os ramos posteriores do paresfenóide, citadas na introdução, ajudam a definir o grupo. As sinapomorfias adicionais mencionadas acima não foram exclusivas do grupo-microlepis. Em Charax, grupo-irmão de Roeboides, o rinoesfenóide está presente ou ausente conforme a espécie, podendo até mesmo variar intraespecificamente como é o caso de C. stenopterus (Cope, 1894) (LuCENA, 1987). O contato ou fusão do órbito-esfenóide com o paresfenóide esteve presente em Charax gibbosus, C. tectifer (Cope, 1870), C. pauciradiatus (Günther, 1864) mas ausente em C. stenopterus e C. condei (Géry \& Knöppel, 1976), indicando variação 
do caráter entre as espécies. O gênero Charax ainda não foi estudado filogeneticamente, portanto a distribuição dos caracteres mencionados é desconhecida. Entretanto, no clado-irmão do grupo-microlepis e nos clados inclusivos mais próximos, o rinoesfenóide está sempre presente e o órbito-esfenóide mantém-se distante do paresfenóide, indicando que a ausência do rinoesfenóide e o íntimo contato entre o órbito-esfenóide e o paresfenóide, estados presentes no grupo-microlepis e em algumas espécies de Charax, é uma aquisição independentemente adquirida nesses táxons.

\section{Clado R. myersii $+R$. araguaito}

Processo transversal da terceira vértebra do aparelho de Weber longo (4.0). Roeboides myersii $+R$. araguaito possuem o processo transversal da terceira vértebra do aparelho de Weber longo, sua extremidade superior dirigida para frente e para cima, ultrapassando a linha horizontal que passa pela região afilada posterior do escáfio. A análise indicou a presença de semelhante caráter como uma aquisição independente em $R$. affinis. Nas demais espécies do grupo-microlepis e no grupo-externo o processo transversal da terceira vértebra do aparelho de Weber é curto, sua extremidade situada bem abaixo na linha horizontal que passa pela região afilada posterior do escáfio (4.1).

Presença de 86 a 99 (média=91,2) escamas perfuradas na linha lateral (8.1). Em R. microlepis e R. margareteae o número de escamas da linha lateral é elevado, 93 a 106 (média=96,7; estado 0). Embora haja sobreposição nos valores extremos, a diferença entre as médias é estatisticamente significativa $(\mathrm{T}=9598,500 ; \mathrm{P}<0,001)$. Diante desta diferença, os limites e suas médias são aqui considerados estados do caráter, sugerindo que representem bases genéticas distintas (RAe, 1998; Weitzman \& Malabarba, 1999). No grupo-externo mais próximo, $R$. dientonito, espécie-irmã de todas as demais do grupoguatemalensis, o número de escamas perfuradas da linha lateral é reduzido, de 51 a 61; outras espécies do grupo-guatemalensis podem apresentar até 86 escamas (estado 2). No grupo-affinis, embora suas espécies não tenham sido analisadas filogeneticamente, o número de escamas não ultrapassa 88 , com a média ao redor de 80 escamas (estado 2 ). Roeboides dispar e Charax possuem número reduzido, até 65 escamas na linha lateral (estado 2). A análise do grupo-externo demonstra claramente que ambos os estados, $1 \mathrm{e}$ 2 , são apomórficos para o grupo-microlepis e definem, respectivamente, os clados $R$. myersii $+R$. araguaito e $R$. margareteae $+R$. microlepis.

Autapomorfias para $R$. myersii. Presença de um poro conspícuo na base do processo neural especializado, próximo ao uróstilo (9.1). Caráter semelhante em $R$. dispar é interpretado como uma aquisição independente. Nas demais espécies do grupomicrolepis e no grupo externo há dois, algumas vezes três, poros conspícuos na base do processo neural especializado próximo ao uróstilo (9.0).

Forame do nervo troclear formado, principalmente, pelo pteroesfenóide (12.1). O referido forame situa-se entre o pteroesfenóide e o órbito-esfenóide. Na condição apomórfica o forame apresenta-se com sua maior parte localizada no pteroesfenóide, mantendo, entretanto, uma porção reduzida no órbito-esfenóide. Nas demais espécies do grupo-microlepis o forame é compartilhado igualmente entre os dois ossos citados (fig. 2) ou, como observado no grupo-externo mais próximo ( $R$. dientonito), localizado totalmente no pteroesfenóide (12.0). Ambos estados são encontrados em Brycon meeki Eigenmann \& Hildebrand, 1918 (WeITZMAN, 1962), indicando que a localização do forame 
troclear pode variar intraespecificamente. Como não foram constatadas variações no caráter quando comparadas as espécies do grupo-microlepis, a condição encontrada em $R$. myersii é aqui considerada autapomórfica. A presença de semelhante condição em $C$. gibbosus e $R$. affinis indica que o estado deste caráter em $R$. myersii é uma reversão ao estado primitivo.

Com a boca aberta, a região dorsal do retroarticular localiza-se posterior à base do côndilo do quadrado (13.0) (fig.3). Em $R$. araguaito e $R$. margareteae e nos representantes mais próximos do grupo-externo, a condição encontrada é aquela em que a região dorsal do retroarticular localiza-se sob a projeção da base do côndilo do quadrado (13.1). A condição observada em $R$. myersii não foi exclusiva, semelhante estado ocorre independentemente em $R$. microlepis. Devido a ocorrência também em C. gibbosus, a presença da região dorsal do retroarticular localizada posterior à base do côndilo do quadrado nas duas primeiras espécies é interpretada como uma condição reversa ao estado primitivo.

Autapomorfias de $R$. araguaito. Projeção mediana do órbito-esfenóide formando uma ponta curva na extremidade (5.1). Na condição apomórfica, a margem superior da projeção mediana do órbito-esfenóide apresenta-se côncava, de modo a formar uma elevação em ponta curva na parte ântero-superior do osso (5.0) (fig. 2). No grupo-externo a margem superior da projeção mediana do órbito-esfenóide é reta; se côncava, não forma uma elevação na parte ântero-superior do osso.

Primeiro espinho hemal com porção distal alargada (7.1). Nos demais representantes do grupo-microlepis e no grupo-externo a porção distal do primeiro espinho hemal é estreita e afilada (7.0).

Nadadeira anal com os primeiros 6 a 7 pterigióforos localizados à frente do primeiro espinho hemal (11.1). Nas demais espécies do grupo-microlepis e no grupo-externo, $R$. dientonito e $R$. dispar, o número de pterigióforos à frente do primeiro espinho hemal varia de 8 a 9 (11.0). O compartilhamento da presença de 6 a 7 pterigióforos entre $R$. affinis e $C$. gibbosus com $R$. araguaito é parcimoniosamente interpretado como uma reversão, constituindo-se em uma autapomorfia para esta última espécie.

Porção final do ângulo-articular, localizada posterior ao local onde articula-se o côndilo do quadrado, afilada e estendendo-se bem além da vertical que passa pela margem posterior do retroarticular (14.0). Em $R$. myersii e $R$. microlepis, grupo-externo e $R$. dientonito, a porção final do ângulo-articular é larga e estende-se pouco além da vertical que passa pela margem posterior do retroarticular ou terminando na mesma vertical (14.1) (fig. 3). A condição presente em $R$. araguaito não é exclusiva, ocorrendo, também, em $R$. margareteae e nos demais integrantes do grupo-externo. Parcimoniosamente, a condição presente em ambas as espécies é um estado reverso primitivo independentemente adquirido e constitui-se em uma autapomorfia para $R$. araguaito.

\section{Clado R. margareteae + R. microlepis}

Presença de 93 a 106 (média=96,7) escamas perfuradas na linha lateral (8.0). Veja comentários sob o clado $R$. myersii $+R$. araguaito.

Porção ínfero-anterior da projeção mediana do órbito-esfenóide com ponta aguda dirigida para baixo e para frente (15.1) (fig. 2). Nos demais representantes do grupomicrolepis e no grupo-externo, a porção ínfero-anterior da projeção mediana do órbitoesfenóide é arredondada (15.0). 
Autapomorfias de $R$. margareteae. Presença de 39 vértebras (6.1). Nas outras espécies examinadas do grupo-microlepis e grupo-externo o número total de vértebras é 38 ou menos (6.0).

Presença do infra-orbital 4 (10.0). Em R. margareteae o infra-orbital 4 é pequeno, fazendo parte somente do contorno interno da série orbital (veja LuCENA, 2000, fig. 4, para condição semelhante em $R$. dayi Steindachner, 1878). Nas demais espécies do grupomicrolepis e no grupo-externo, o infra-orbital 4 está ausente (10.1). O compartilhamento do infra-orbital 4 com as espécies do grupo-guatemalensis, indica que a presença deste osso em $R$. margareteae é uma reversão à condição primitiva, constituindo-se em uma autapomorfia.

Porção final do articular, localizada posteriormente ao local onde articula-se o côndilo do quadrado, afilada e estendendo-se bem além da vertical que passa pela margem posterior do retroarticular (14.0). Veja comentários em $R$. araguaito.

Autapomorfia para $R$. microlepis. Com a boca aberta, a região dorsal do retroarticular localiza-se posterior à base do côndilo do quadrado (13.0). Veja comentários em R. myersii.

\section{Chave para as espécies de Roeboides grupo-microlepis}

1. Número total de rastros no primeiro arco branquial de 22 a 26 (média $=23,8$ ); número de rastros no ramo inferior do primeiro arco branquial de 14 a 16 (média=15,0); bacia do rio Amazonas. ..R. myersii Gill, 1870

Número total de rastros no primeiro arco branquial de 19 a 23; número total de rastros no ramo inferior do primeiro arco branquial de 12 a 14 .

2. De 93 a 106 escamas perfuradas na linha lateral (média=96,7); de 24 a 29 escamas acima da linha lateral (média $=29,0)$.

De 86 a 96 escamas perfuradas na linha lateral (média=90,3); de 20 a 26 escamas acima da linha lateral (média $=23,4$ ); bacia do rio Orinoco. R. araguaito sp. nov.

3. Em exemplares acima de $130,0 \mathrm{~mm} \mathrm{CP}$, altura do corpo de $35,1 \%$ a $41,7 \%$ do CP (média $=37,9 \%$ ); altura do pedúnculo caudal de $7,8 \%$ a $9,0 \%$ do CP (média $=8,6 \%$ ); diâmetro da órbita de $22 \%$ a 28,5\% (média=25,3\%); bacia dos rios Parnaíba e PindaréMearim.

R. margareteae sp. nov.

Em exemplares acima de $115,0 \mathrm{~mm} \mathrm{CP}$, altura do corpo de $39,3 \%$ a $50,5 \%$ do $\mathrm{CP}$ média $=43,9 \%$ ); altura do pedúnculo caudal de $8,7 \%$ a $9,9 \%$ do CP (média $=9,4 \%$ ); diâmetro da órbita de $25,7 \%$ a 31,5\% do comprimento da cabeça (média=28,5\%); bacia dos rios Paraguai, e médio e baixo Paraná........R. microlepis (Reinhardt, 1851)

\section{Roeboides araguaito sp. nov.}

(Figs. 4-6)

Material-tipo. Holótipo, VENEZUELA: Delta Amacuro, río Orinoco, laguna na margem norte do rio, ao norte do riacho Araguaito, aprox. 0840'42"N-62 00'24”W, MBUCV 29670 (CP $87,3 \mathrm{~mm}$ ). Parátipos: COLÔMBIA, rio Metica, cerca de $3 \mathrm{~km}$ a sudeste da Fazenda Mozambique, sistema do rio Meta, $03^{\circ} 57^{\prime} \mathrm{N}-73^{\circ} 02^{\prime} \mathrm{W}$, ANSP 131472 (6, CP 77,3-82,5 mm; 2 exemplares, 77,381,1 mm CP, dc); Meta: rio Guaviare, USNM 181353 (2, CP 97,8-101,2 mm). VENEZUELA,

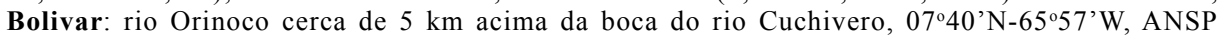
159986 (1, CP 71,8 mm); Amazonas: rio Orinoco, El Burro, 06² 12’N-67²6’W, ANSP 159998 (2, CP 87,6-90,6 mm); Anzoátegui: lago Tineo, sistema do rio Orinoco, Soledad, $08^{\circ} 11^{\prime} 25^{\prime \prime} \mathrm{N}-63^{\circ}$ 28'20'W, ANSP 166616 (1, CP 89,8 mm); Playa Blanca, Soledad, sistema do rio Orinoco, 0809'10’N- 
633'00"W, ANSP 166617 (2, CP 77,8-79,9 mm); laguna Terecaya, Soledad, 08¹1'30"N$63^{\circ} 27^{\prime} 20^{\prime \prime} \mathrm{W}$, ANSP 166618 (1, CP 72,4 mm); laguna Terecaya, sistema do rio Orinoco, Soledad, $08^{\circ} 11^{\prime} 30^{\prime \prime} \mathrm{N}-63^{\circ} 27^{\prime} 20^{\prime \prime} \mathrm{W}$, ASNP 166619 (1, CP 84,3 mm); laguna Terecaya, Soledad, 08¹0’N633' 'W, MCP 26490 (2, CP 70,2-74,2 mm); rio Apure, cerca de $2 \mathrm{~km}$ a leste da ponte em San Fernando de Apure, MZSP 36490 (1, CP 110,9 mm). Guarico: Cabruta, El Burro, bacia do rio Orinoco, 07³9'30'N66ำ'30"W, ANSP 166620 (1, CP 78,7 mm); Delta Amacuro, rio Orinoco, laguna na margem norte do rio, ao norte do riacho Araguaito, aprox. 08 $400^{\prime} 42^{\prime \prime} \mathrm{N}-62^{\circ} 00^{\prime} 24^{\prime \prime} \mathrm{W}, \mathrm{MCP} 26489$ (1, CP 81,2 mm).

Diagnose. Segundo a análise filogenética, a projeção mediana do órbito-esfenóide formando uma ponta curva na extremidade e o primeiro espinho hemal com porção distal alargada são duas autapomorfias exclusivas para a $R$. araguaito. Essa espécie distinguese ainda de $R$. myersii pelo menor número de rastros no ramo inferior do primeiro arco branquial, 12 a 14 (média=13,1) contra 14 a 16 (média=15,0) (fig. 5) e pelo número total de rastros no primeiro arco branquial, 19 a 23 (média $=20,9)$ contra 22 a 26 (média=23,8). De $R$. margareteae distingue-se pelo maior comprimento pré-peitoral $28,6 \%$ a $32,6 \%$ do $\mathrm{CP}$ (média $=30,2 \%$ ) contra 25,8\% a 28,4\% do CP (média=27,2\%) em exemplares acima de 130 mm CP; maior diâmetro da órbita, $29,8 \%$ a 36,2\% do comprimento da cabeça (média=33,0\%) contra $22,0 \%$ a $28,5 \%$ do comprimento da cabeça (média $=25,3 \%$ ) em exemplares acima de $130 \mathrm{~mm}$ CP, e menor comprimento da maxila superior, $53,1 \%$ a $59,3 \%$ do comprimento da cabeça (média= $57,1 \%$ ) contra $58,4 \%$ a $65,1 \%$ do comprimento da cabeça (média $=60,2 \%$ ). De $R$. microlepis, $R$. araguaito é distinta pelo menor número de escamas acima da linha lateral, 20 a 26 (média $=23,4)$ contra 27 a 32 (média=29,0); menor número de escamas perfuradas da linha lateral, 86 a 96 (média $=90,0)$ contra 92 a 106 (média=98,4); menor altura do corpo, $32,6 \%$ a $41,0 \%$ do CP (média $=37,4 \%$ ) contra $40,3 \%$ a $50,5 \%$ do $\mathrm{CP}$ (média $=45,4 \%$ ) e maior comprimento pré-peitoral, $28,6 \%$ a $32,6 \%$ do CP (média $=30,2 \%$ ) contra $25,4 \%$ a $29,4 \%$ do CP (média $=27,9 \%$ ) em exemplares acima de $115 \mathrm{~mm} \mathrm{CP}$.

Descrição. Dados morfométricos e merísticos (tab. II). Corpo alto. Perfil dorsal formando uma gibosidade desde o terço posterior da órbita até a origem da nadadeira dorsal, a partir daí, reto e declinando abruptamente até o final da base dessa nadadeira; deste ponto continua reto e segue declinando suavemente até o início do pedúnculo caudal onde, após sutil concavidade, eleva-se até a base dos raios superiores da nadadeira caudal. Perfil dorsal da cabeça reto ou levemente convexo sob o terço posterior da órbita até o final do focinho. Perfil ventral marcadamente convexo desde a ponta da mandíbula até a origem da nadadeira anal, reto a partir daí até o pedúnculo caudal (fig. 4). Pseudotímpano entre a primeira e a segunda costelas pleurais, algumas vezes não distinguível. Boca terminal. Maxilar longo, extremidade posterior situando-se entre as verticais que passam pela metade da órbita e sua margem posterior, com 7 a 17 dentes, sendo, 4 a 8 dentes cônicos de base larga na margem ventral, seguidos de um ou dois dentes mamiliformes deslocados para a superfície externa, mais 3 a 8 dentes mamiliformes na margem ventral. Pré-maxilar com um dente mamiliforme dirigido para frente na sua superfície externa (= dente D1, LuCENA, 1998), um dirigido para fora, localizado no ramo lateral (= dente D2, LUCENA, 1998) e um menor, entre ambos, dirigido para frente (= dente D3 em LuCENA, 1998), todos robustos e sem cúspides. Mais internamente, os dentes não têm arranjo definido, diferindo, inclusive, entre os pré-maxilares direito e esquerdo. No arranjo mais comum, distinguem-se duas fileiras de dentes: a primeira com 4 a 6 dentes mamiliformes, geralmente desalinhada e, algumas vezes, com um, ou dois, dentes dirigidos para frente e a segunda, mais interna, com 4 a 7 dentes menores; ambas complementam- 
Tabela II. Medidas e contagens de Roeboides araguaito sp. nov., holótipo, MBUC-V-29670, e $R$. margareteae, sp. nov., holótipo MZSP 38722. Medidas dos holótipos em valores absolutos (N, número de exemplares; *, contagens aproximadas).

\begin{tabular}{|c|c|c|c|c|c|c|c|c|c|c|}
\hline & \multicolumn{5}{|c|}{ Roeboides araguaito } & \multicolumn{5}{|c|}{ Roeboides margareteae } \\
\hline & \multirow[b]{2}{*}{ Holótip } & \multirow[b]{2}{*}{$\mathrm{N}$} & \multicolumn{2}{|c|}{ Limites } & \multirow[b]{2}{*}{ Média } & \multirow{2}{*}{\multicolumn{2}{|c|}{ Holótipo N }} & \multicolumn{2}{|c|}{ Limites } & \multirow[b]{2}{*}{ rMédia } \\
\hline & & & Inferior & Superior & & & & Inferior & Superior & \\
\hline \multirow[t]{2}{*}{ Comprimento padrão (mm) } & 87,3 & 22 & 70,2 & 110,9 & 83,4 & 126,4 & 24 & 64,2 & 184,7 & 133,1 \\
\hline & \multicolumn{10}{|c|}{ Porcentagens do comprimento padrão } \\
\hline Altura do corpo & 33,3 & 19 & 32,6 & 41,0 & 37,4 & 48,7 & 24 & 35,1 & 41,7 & 37,9 \\
\hline o pré-dorsal & 42,2 & 22 & 35,3 & 52,4 & 49 & 65,9 & 24 & 49,6 & 52,4 & 51,0 \\
\hline Comprimento pré-a & 44,3 & 22 & 38,0 & 54,4 & 50 & 67,0 & 24 & 47,4 & 53,0 & 49,9 \\
\hline Comprimento pré-peitoral & 25,0 & 22 & 28,6 & 32,6 & 30 & 35,8 & 24 & 25,8 & 29,6 & 27,6 \\
\hline Comprimento pré-ventral & 33,5 & 22 & 27,6 & 41,6 & 38,2 & 48,8 & 24 & 34,0 & 39,0 & 36,4 \\
\hline Compr. pedúnculo caudal & 8,2 & 22 & 8,4 & 11,0 & 9,9 & 12,3 & 21 & 8,9 & 10,6 & 9,6 \\
\hline Altura pedúnculo caudal & 7,0 & 22 & 7,1 & 9,3 & 8,2 & 12,2 & 21 & 7,8 & 9,7 & 8,6 \\
\hline \multirow[t]{2}{*}{ Comprimento cabeça } & 23,0 & 22 & 26,3 & 29,9 & 28,0 & 33,9 & 24 & 25,0 & 28,2 & 26,3 \\
\hline & \multicolumn{10}{|c|}{ Porcentagens do comprimento da cabeça } \\
\hline Comprimento focinho & 5,6 & 22 & 22,8 & 38,5 & 25,2 & 9,3 & 23 & 22,5 & 28,7 & 25,6 \\
\hline Diâm & 7,1 & 22 & 29,8 & 2 & 33 & 9,2 & 23 & 22,0 & 5,5 & 26,5 \\
\hline Comprimento maxila & 13,2 & 22 & 53,1 & 59,3 & 57,1 & 19,8 & 24 & 58,4 & 65,1 & 61,5 \\
\hline \multirow[t]{2}{*}{ Espaço inter-orbital } & 6,1 & 22 & 24,2 & 30,3 & 26,8 & 8,2 & 24 & 21,1 & 27,9 & 25,3 \\
\hline & \multicolumn{10}{|c|}{ Contagens } \\
\hline $\mathrm{N}^{\circ}$ raios nad. anal & 52 & 22 & 45,0 & 53,0 & 49,5 & 48 & 23 & 46,0 & 53,0 & 49,1 \\
\hline $\mathrm{N}^{\circ}$ rai & 12 & 22 & 12,0 & & & 14 & 23 & 12,0 & 5,0 & 14,0 \\
\hline $\mathrm{N}^{\circ}$ rastros ramo inferior & 15 & 22 & 12,0 & & 13, & 9 & 24 & 13,0 & 14,0 & 13,1 \\
\hline $\mathrm{N}^{\circ}$ rastros ramo superior & 13 & 22 & 7,0 & 9,0 & 7,7 & 14 & 24 & 7,0 & 8,0 & 7,7 \\
\hline $\mathrm{N}^{\circ}$ total rastros & 21 & 22 & 19,0 & 23,0 & 20,9 & 22 & 23 & 20,0 & 22,0 & 20,8 \\
\hline $\mathrm{N}^{\circ}$ esc. perf. linha lateral & 92 & 20 & 86,0 & 96,0 & 90,3 & $94 *$ & 11 & 93,0 & 99,0 & 95,0 \\
\hline $\mathrm{N}^{\circ}$ esc. acima linha lateral & 24 & 18 & 20,0 & 26,0 & 23,4 & 25 & 10 & 24,0 & 29,0 & 25,8 \\
\hline $\mathrm{N}^{\circ}$ esc. abaixo linha lateral & 20 & 20 & 17,0 & 21,0 & 18,9 & 17 & 14 & 17,0 & 20,0 & 18,4 \\
\hline $\mathrm{N}^{\circ}$ esc. redor ped. caudal & 26 & 17 & 26,0 & 29,0 & 26,9 & $27 *$ & 6 & 25,0 & 28,0 & 26,7 \\
\hline
\end{tabular}

se para ocupar toda a margem ventral do pré-maxilar. Cúspides laterais, pequenas que podem estar ausentes. Dentário com dois dentes mamiliformes externos sem cúspides, um próximo à sínfise, dirigido para frente (= dente D4, LUCENA, 1998) e outro, mais lateral, dirigido para frente e para fora (= dente D5, LuCENA, 1998). A fileira principal de dentes do dentário é composta por um dente mamiliforme sinfiseano, seguido de 5 a 7 dentes cônicos robustos e um mamiliforme, todos com duas pequenas cúspides laterais que podem estar ausentes; seguem-se cerca de 10 a 16 dentes cônicos robustos.

Nadadeira dorsal, ii +9 raios, sua origem na vertical que passa pela origem da nadadeira anal, ou logo atrás. Nadadeira peitoral, i+12-16 raios, seu raio mais longo alcançando a origem da nadadeira anal ou ultrapassando levemente nos jovens. Margem póstero-inferior do cleitro com um entalhe desenvolvido formando uma projeção curta dirigida para trás e de extremidade arredondada; região ântero-inferior com uma projeção aguda conspícua dirigida para frente. Nadadeira ventral, $i+7$ raios; raio mais longo ultrapassando a origem da nadadeira anal, alcançando no máximo o sexto raio ramificado desta nadadeira. Nadadeira anal, iv-v+45-53 raios, com uma bainha formada por 5 a 7 fileiras de escamas percorrendo quase toda sua base; tanto na nadadeira ventral quanto 


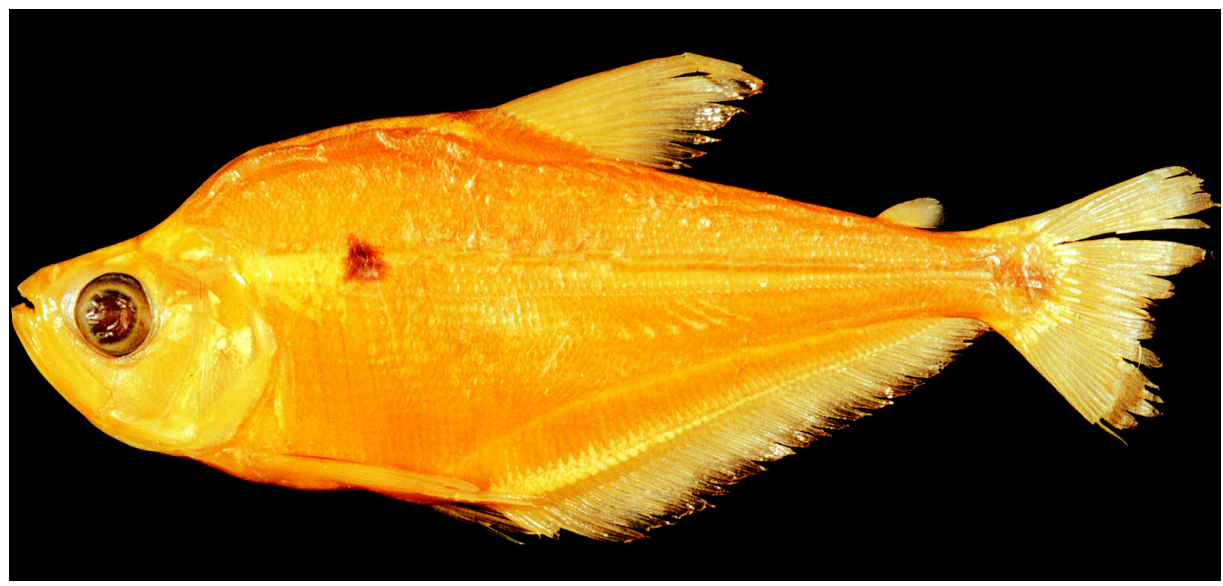

Fig. 4. Roeboides araguaito, holótipo MUCV 26670, 87,3 $\mathrm{mm} \mathrm{CP}$, laguna na margem norte do rio Orinoco, ao norte do riacho Araguaito, Delta Amacuro, Venezuela.

na anal não foram visualizados raios com ganchos. Nadadeira adiposa presente, sua origem situando-se entre as verticais que passam na região entre $\mathrm{o} 40^{\circ}$ ao $45^{\circ}$ raio ramificado da nadadeira anal. Nadadeira caudal $i+17+i$ raios principais com extremidade em forma de meia-lua, sendo mais furcada nos jovens. Vértebras pré-caudais, 15; caudais, 22 em 2 exemplares examinados.

Colorido em álcool. Coloração geral do corpo castanho-clara. Dorso escurecido. Uma mancha umeral escura, conspícua. Mancha escura no pedúnculo caudal presente, às vezes muito fraca, localizada à frente da base dos raios da nadadeira caudal. Uma faixa escura longitudinal desde a região superior da mancha umeral até a mancha do pedúnculo caudal, às vezes difusa ou ausente. Em alguns exemplares, a região lateral do corpo abaixo da faixa escura longitudinal, apresenta coloração prateada que pode se estender à porção lateral da cabeça, atrás e sob a órbita. Todas as nadadeiras claras com esparsos cromatóforos escuros distribuídos sobre as membranas interradiais.

Distribuição. Bacia do rio Orinoco (fig. 6).

Etimologia. O substantivo em aposição araguaito é em alusão ao riacho próximo ao local onde foi coletado o holótipo.

\section{Roeboides margareteae sp. nov.}

(Figs. 5-7)

Material-tipo. Holótipo, BRASIL, Maranhão: lago do Viana, sistema do rio Pindaré-Mearim, MZSP 38722 (CP 126,4 mm). Parátipos: BRASIL, Piauí: Teresina, rio Jaguaribe, ANSP 82289 (1, CP $181,0 \mathrm{~mm}$ ); rio Parnaíba na Barra do Longa, próximo a Buriti dos Lopes, $03^{\circ} 11^{\prime} \mathrm{S}-41^{\circ} 50^{\prime} \mathrm{W}, \mathrm{MCZ}$ 46787 (1, CP 64,2 mm); Teresina, rio Parnaíba, MZSP 5102 (1, CP 71,0 mm, dc); idem, UFPI 601 (1, 

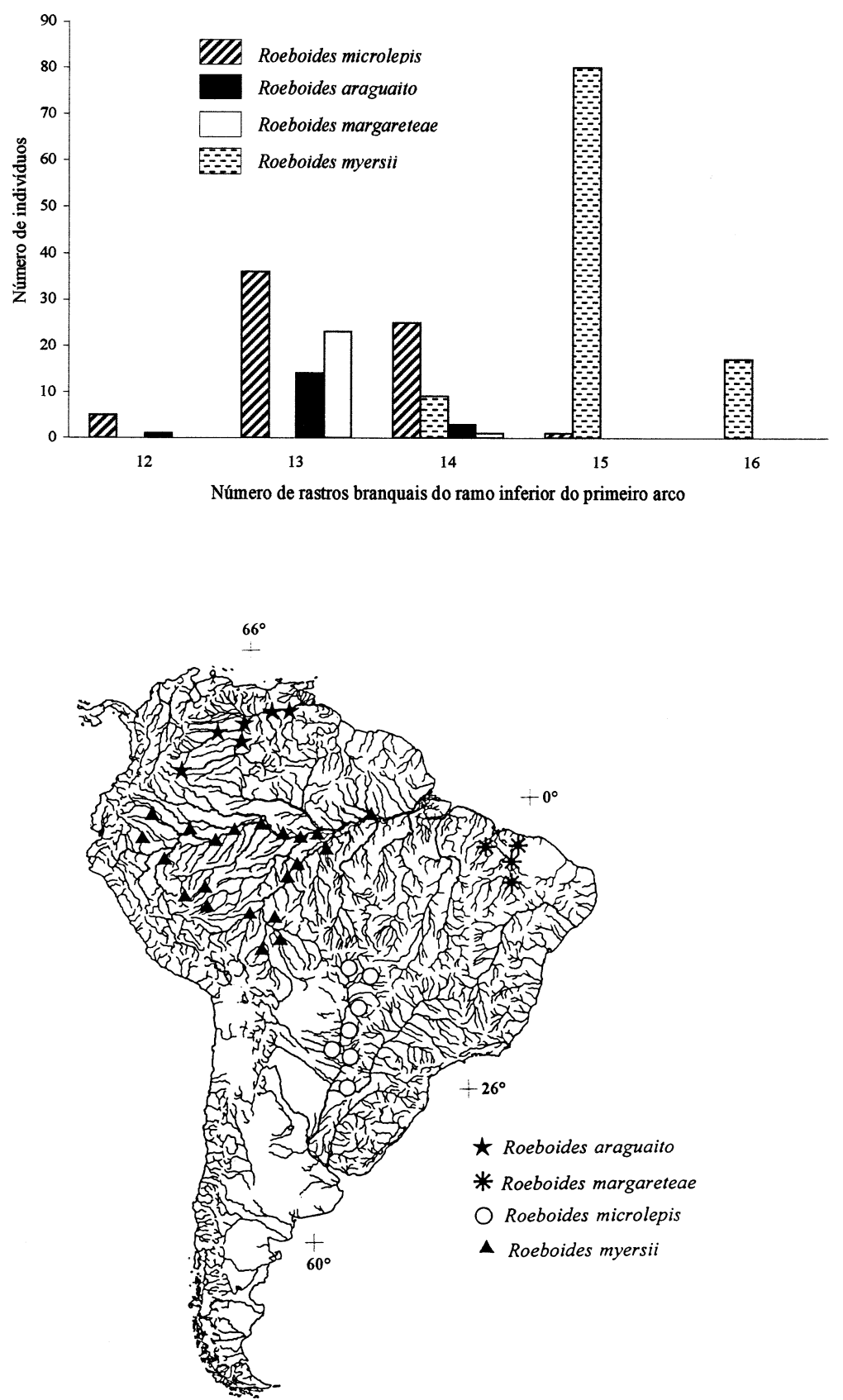

Figs. 5, 6. 5, Distribuição da freqüência do número de rastros branquiais do ramo inferior do primeiro arco; 6, distribuição das espécies de Roeboides grupo-microlepis (um ponto pode indicar mais de uma localidade). 


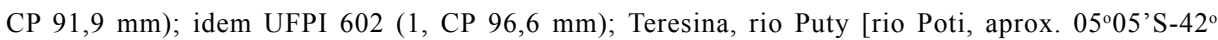
49'W] USNM 119942 (13, CP 115,3-162,5 mm; 1 exemplar, 115,3 mm CP, dc); San Gonçallo [atual Amarante, aprox. 06 $\left.{ }^{\circ} 14^{\prime} \mathrm{S}-42^{\circ} 51^{\prime} \mathrm{W}\right]$, USNM 119944 (3, CP 133,6-184,7 mm); Ceará: Russas, rio Jaguaribe, ANSP 95879 (2, CP 129,5-136,2 mm).

Diagnose. A análise filogenética indicou a presença de 39 vértebras totais como autapomorfia exclusiva para $R$. margareteae. Esta espécie distingue-se de $R$. microlepis, pelo menor espaço interorbital, $21,1 \%$ a $27,9 \%$ (média $=25,3 \%$ ) do comprimento da cabeça, contra $24,9 \%$ a $33,1 \%$ (média $=29,0 \%$ ), especialmente quando comparados exemplares acima de $115 \mathrm{~mm}$ CP e pelo menor número de escamas abaixo da linha lateral, 17 a 20 (média $=18,5)$ contra 19 a 23 (média $=20,9)$. De $R$. araguaito distingue-se pelo menor comprimento pré-peitoral $25,8 \%$ a $28,4 \%$ do $\mathrm{CP}$, em exemplares acima de $130 \mathrm{~mm} \mathrm{CP}$ (média $=27,2 \%$ ) contra $28,6 \%$ a 32,6\% do CP (média=30,2\%); menor diâmetro da órbita, $22,0 \%$ a $28,5 \%$ do comprimento da cabeça (média $=25,3 \%$ ), em exemplares acima de 130 mm CP, contra $29,8 \%$ a $36,2 \%$ do comprimento da cabeça (média $=33,0 \%$ ), e maior comprimento da maxila superior, $58,4 \%$ a $65,1 \%$ do comprimento da cabeça (média $=61,5 \%$ ) contra $53,1 \%$ a $59,3 \%$ do comprimento da cabeça (média=57,1\%). De $R$. myersii, $R$. margareteae distingue-se, especialmente considerando-se exemplares acima de $130 \mathrm{~mm}$ CP, pelo menor comprimento pré-ventral, $34,0 \%$ a $37,4 \%$ do CP (média $=35,8 \%$ ) contra $36,4 \%$ a $42,2 \%$ do CP (média $=38,6 \%$ ); maior comprimento da maxila, $60,2 \%$ a $65,1 \%$ do comprimento da cabeça (média $=62,0 \%$ ), contra $50,3 \%$ a $63,7 \%$ (média $=56,4 \%$ ) e menor espaço interorbital, $21,1 \%$ a $27,9 \%$ do comprimento da cabeça (média=25,2\%), contra $25,3 \%$ a 32,0\% (média $=28,3 \%$ ). Ainda de $R$. myersii, distingue-se pelo menor número de rastros branquiais no ramo inferior do primeiro arco branquial, 13 (raramente 14) (média=13,1) contra 14 a 16 (média=15,0) (fig. 5).

Descrição. Dados morfométricos e merísticos (tab. II). Corpo alto. Perfil dorsal formando uma gibosidade desde o terço posterior da órbita até a origem da nadadeira dorsal, a partir daí, reto e declinando abruptamente até o final da base dessa nadadeira; deste ponto continua reto e segue declinando suavemente até o início do pedúnculo caudal onde, após sutil concavidade, eleva-se até a base dos raios superiores da nadadeira caudal. Perfil dorsal da cabeça reto ou levemente convexo sob o terço posterior da órbita até o final do focinho. Perfil ventral marcadamente convexo desde a ponta da mandíbula até a origem da nadadeira anal, reto a partir daí até o pedúnculo caudal (fig. 7). Pseudotímpano entre a primeira e a segunda costelas pleurais, algumas vezes não distinguível. Boca terminal. Maxilar longo, extremidade posterior situando-se entre as verticais que passam pela metade da órbita e sua margem posterior, 8 a 13 dentes, sendo 4 a 5 cônicos de base larga na margem ventral, seguidos de um ou dois mamiliformes deslocados para a superfície externa, mais 3 a 7 dentes mamiliformes na margem ventral. Pré-maxilar com um dente mamiliforme dirigido para frente na sua superfície externa (= dente D1, LuCENA, 1998) e um dirigido para fora, localizado no ramo lateral (= dente D2, LUCENA, 1998), ambos robustos e sem cúspides. Mais internamente os dentes não têm arranjo definido, diferindo inclusive entre os pré-maxilares direito e esquerdo. No arranjo mais comum, distinguem-se duas fileiras de dentes: a primeira, 5 a 7 dentes mamiliformes, geralmente desalinhada, e a segunda mais interna, 5 a 7 dentes menores; ambas complementam-se para ocupar toda a margem ventral do pré-maxilar. Cúspides laterais, pequenas que podem estar ausentes. Dentário com dois dentes mamiliformes externos sem cúspides, um próximo à sínfise, dirigido para frente (= dente D4, LuCENA, 1998) e 
outro mais lateral, dirigido para frente e para fora (=dente D5, LuCENA, 1998). A fileira principal de dentes do dentário é composta por um dente mamiliforme sinfiseano, seguido de 6 a 7 dentes cônicos robustos e um mamiliforme, todos com duas pequenas cúspides laterais que podem estar ausentes; segue-se cerca de 8 a 12 dentes cônicos robustos.

Nadadeira dorsal, ii +9 raios, sua origem na vertical que passa pela origem na nadadeira anal; mais atrás em jovens menores de $69,0 \mathrm{~mm}$ CP. Nadadeira peitoral, i+12-15 raios, seu raio mais longo alcançando a origem da nadadeira anal ou a ultrapassando levemente nos jovens. Margem póstero-inferior do cleitro com um entalhe desenvolvido formando uma projeção curta dirigida para trás e de extremidade arredondada; região ântero-inferior com uma projeção aguda conspícua dirigida para frente. Nadadeira ventral, i+7 raios; raio mais longo ultrapassando a origem da nadadeira anal, podendo alcançar, no máximo o sexto raio desta nadadeira; machos com ganchos nas margens internas dos seis primeiros raios ramificados. Nadadeira anal, iv-v+46-53 raios, com uma bainha formada por 7 a 10 fileiras de escamas percorrendo toda sua base; machos com ganchos situados na margem posterior dos quarenta e dois a quarenta e cinco primeiros raios. Nadadeira adiposa presente, sua origem situando-se entre as verticais que passam na região entre o $40^{\circ}$ ao $45^{\circ}$ raio ramificado da nadadeira anal. Nadadeira caudal $i+17+i$ raios principais com extremidade em forma de meia-lua, sendo mais furcada nos jovens. Vértebras précaudais 16; caudais, 23 em 1 exemplar examinado.

Colorido em álcool. Os exemplares examinados se encontram mal preservados. Em geral a coloração do corpo é castanho-clara. Dorso escurecido. Uma mancha umeral escura, conspícua. Mancha no pedúnculo caudal presente, às vezes inconspícua, localizada à frente da base dos raios da nadadeira caudal. Uma faixa longitudinal escura desde a região superior da mancha umeral até a mancha do pedúnculo caudal às vezes difusa ou ausente. Em alguns exemplares, a região lateral do corpo, abaixo da faixa longitudinal escura, apresenta coloração prata que pode se estender à porção lateral da cabeça, atrás e sob a órbita. Todas as nadadeiras claras com esparsos cromatóforos escuros distribuídos sobre as membranas interradiais. Brasil.

Distribuição. Drenagem dos rios Parnaíba e Pindaré-Mearim (fig. 6), nordeste do

Etimologia. O nome específico, margareteae, em homenagem à minha esposa Zilda Margarete.

\title{
Roeboides microlepis (Reinhardt, 1851)
}

\author{
(Figs. 5, 6, 8)
}

Epycirtus gibbosus; Valenciennes in Cuvier \& Valenciennes, 1850:43 (parte); Castelnau, 1855:60.

Epycirtus microlepis ReINHARDT, 1851:46 (localidade-tipo: "Des eaux douces de la province de Minas Geraes"; restringida no presente trabalho para o sistema do rio Paraguai).

Anacyrtus (Rhaeboides) (sic) bonariensis Steindachner, 1879:23 (localidade-tipo: "La Plata, Provinz Buenos-Ayres"). Syn. nov.

Roeboides microlepis; Eigenmann, 1910:445 (designação espécie-tipo); LucENA, 1988:34 (discussão da procedência do holótipo).

Material-tipo. Holótipo, BRASIL: localidade-tipo restringida para o rio Paraguai, MNHN A.8657 (CP $167 \mathrm{~mm}$ ). Mato Grosso: rio Paraguai, Cáceres e arredores, MCP 15808 (4, CP 89,4-159,9 mm; 1 exemplar, 89,4 mm CP, dc); Santo Antônio do Leverger, rio Cuaibá na baía do Poço, MCP 26065 (4, CP 65,9-104,1 mm; 1 exemplar, 65,9 mm CP, dc); Santo Antônio do Leverger, Volta Grande, rio 
Cuiabá, MZSP 14736 (1, CP 93,9 mm); Melgaço, Sangradouro Grande, rio Cuiabá, MZSP 19800 (1, CP 125,4 mm); Melgaço, boca do Croará, rio Cuiabá, MZSP 19837 (3, CP 91,0-100,0 mm); Corumbá, quinta ponte ao sul do rio Miranda, MZSP 19895 (1, CP 117,9 mm); Santo Antônio do Leverger, Volta Grande, rio Cuiabá, MZSP 27687 (2, CP 102,2-103,7 mm); Cáceres e arredores, rio Paraguai, MZSP 44412 (4, CP 90,3-101,2 mm). PARAGUAI, Central: rio Paraguai, cerca de $1 \mathrm{~km}$ ao sul de Puente Remanso, 2517'36”S-52³3’0”W, UMMZ 208093 (9, CP 92,0-130,0 mm); Concepción: área alagada

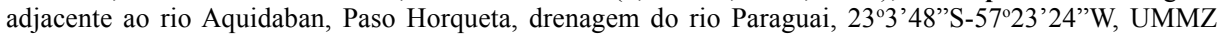
207881 (5, CP 96,8-160,1 mm); rio Aquidaban em Paso Horqueta, cerca de $24 \mathrm{~km}$ de Loreto, drenagem do rio Paraguai, 233'48"S-57²3'24"W, UMMZ 207805 (3, CP 103,9-186,7 mm); Cordillera: lago Ypacarai, San Bernardino, NRM 22571 (1, CP 131,5 mm); Assunção, rio Paraguai, NRM 15971 (1, CP 167,0 mm); Presidente Hayes: rio Aguaray-Guazu, km 117 na estrada transpantaneira, MCP 14603 (1, CP 115,0 mm); estância Juan Salazar, MNHN 1380 (5, CP 48,5-66,4

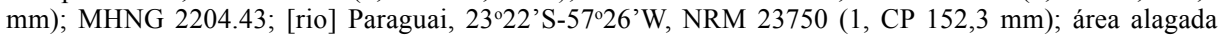

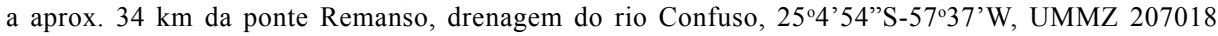
$(15, \mathrm{CP} 118,2-168,0 \mathrm{~mm})$; rio Montelindo, drenagem do rio Paraguai, 235' $42^{\prime \prime} \mathrm{S}-58^{\circ} 27^{\prime} 36^{\prime} \mathrm{W}$, UMMZ 207240 (2, CP 99,2-105,7 mm); poça adjacente ao lago cerca de $6 \mathrm{~km}$ a leste da estrada transchaco

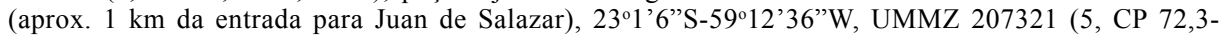
172,6 mm). ARGEnTINA, Posadas: arroio Martines, MCP 10149 (1, CP 63,6 mm).

Diagnose. A análise filogenética mostrou que a presença da região dorsal do retroarticular localizando-se posterior a base do côndilo do quadrado (13.0) distingue $R$. microlepis de $R$. araguaito e $R$. margareteae. Roeboides microlepis distingue-se de $R$. myersii pelo menor número total de rastros branquiais e número de rastros do ramo inferior do primeiro arco, respectivamente, 19 a 23 (média $=21,0)$ e 12 a 14 (média=13,2) contra 22 a 26 (média $=23,8$ ) e 14 a 16 (média $=15,0$ ) (fig. 5); distingue-se ainda dessa espécie por apresentar o infraorbital 3 curto, não alcançando a borda inferior do préopérculo, contra infraorbital 3 longo, alcançando a borda inferior do pré-opérculo em exemplares acima de $135 \mathrm{~mm}$ CP. Roeboides microlepis distingue-se de $R$. margareteae pelos caracteres dados em chave por ter maior espaço interorbital, $24,9 \%$ a $33,1 \%$ (média $=27,4 \%$ ), especialmente quando comparados exemplares acima de $115 \mathrm{~mm} \mathrm{CP}$, contra $21,1 \%$ a $27,9 \%$ (média $=25,2 \%$ ) e maior número de escamas abaixo da linha lateral, 19 a 23 (média=20,9) contra 17 a 20 (média=18,5). De $R$. araguaito, $R$. microlepis distinguese pelo menor diâmetro orbital, quando comparados exemplares acima de $130 \mathrm{~mm} \mathrm{CP}$, $25,7 \%$ a $31,5 \%$ (média $=28,5 \%$ ) contra $29,8 \%$ a $36,2 \%$ (média $=33,0 \%$ ); pelo menor comprimento pré-peitoral $25,4 \%$ a $29,4 \%$ do CP (média $=27,9 \%$ ) em exemplares acima de $130 \mathrm{~mm} \mathrm{CP}$ contra $28,6 \%$ a $32,6 \%$ do CP (média $=30,2 \%$ ); maior altura do corpo, $39,3 \%$ a $50,5 \%$ do CP (média=43,9\%) contra 32,6\% a 41,0\% do CP (média=37,4\%); maior número de escamas perfuradas na linha lateral, 94 a 105 (média $=98,4)$ contra 86 a 96 (média $=90,3$ ) e de escamas acima da linha lateral, 27 a 32 (média $=29,0)$ contra 20 a 26 (média=23,4).

Descrição. Dados morfométricos e merísticos (tab. III). Corpo alto. Perfil dorsal formando uma gibosidade desde o terço posterior da órbita até a origem da nadadeira dorsal; a partir daí, reto e declinando abruptamente até o final da base dessa nadadeira, desse ponto continua reto e segue declinando suavemente, até o início do pedúnculo caudal onde, após sutil concavidade, eleva até a base dos raios superiores da nadadeira caudal. Perfil dorsal da cabeça em exemplares adultos reto ou levemente convexo sob o terço posterior da órbita até o final do focinho; jovens com perfil notadamente convexo desde as narinas até o final do focinho. Perfil ventral marcadamente convexo desde a ponta da mandíbula até a origem da nadadeira anal, reto a partir daí até o pedúnculo caudal (fig. 8). Pseudotímpano entre a primeira e a segunda costelas pleurais. Boca 


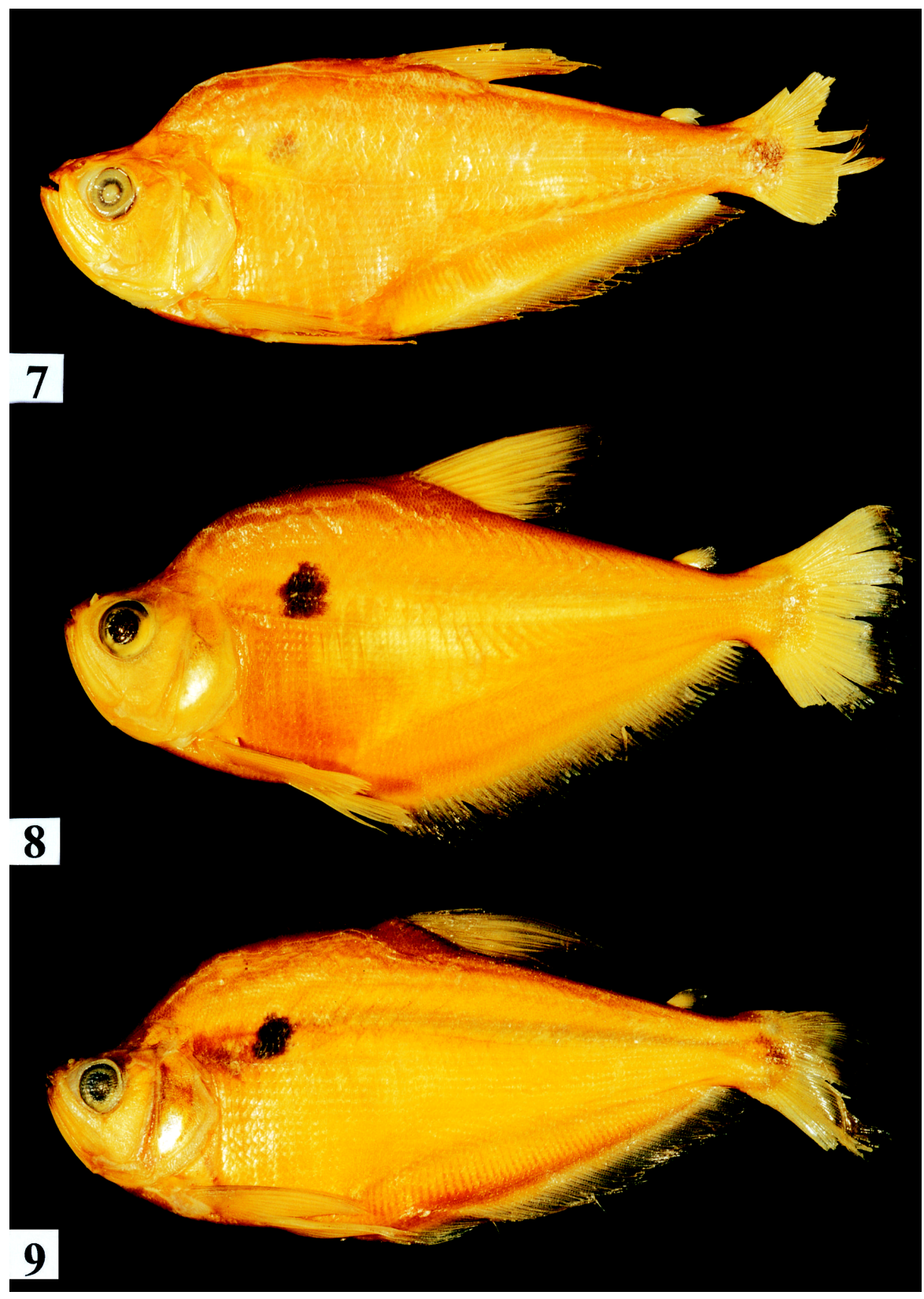

Figs. 7-9. 7, Roeboides margareteae, holótipo MZSP 38722, 126,4 mm CP, lago do Viana, sistema do rio Pindaré-Mearim, Maranhão, Brasil; 8, Roeboides microlepis: MCP 15808, Cáceres, rio Paraguai, Mato Grosso, 159,9 mm CP; 9, Roeboides myersii,USNM 124410 rio Ampiyacu, Peru, 139,8 mm CP. 
terminal. Maxilar longo, com 6 a 20 dentes, extremidade posterior entre as verticais que passam pela metade da órbita e sua margem posterior; jovens somente com dentes cônicos de base larga, e todos situados na margem ventral do osso; exemplares a partir de 64,0 mm CP com 5 a 8 dentes cônicos de base larga na margem ventral, seguidos de um ou dois dentes mamiliformes deslocados para a superfície externa, mais 2 a 10 dentes mamiliformes que reduzem-se em número ontogeneticamente. Pré-maxilar com um dente mamiliforme dirigido para frente na sua superfície externa (= dente D1, LuCENA, 1998), um dirigido para fora, localizado no ramo lateral (= dente D2, LUCENA, 1998) e um, menor entre ambos, dirigido para frente (= dente D3, LuCENA, 1998). Esse último com posição variável, podendo estar alinhado com os dentes D1 e D2 ou em um plano acima ou abaixo. Todos robustos e sem cúspides. Mais internamente os dentes não têm arranjo definido, diferindo inclusive entre os pré-maxilares direito e esquerdo. No arranjo mais comum, distinguemse duas fileiras de dentes, algumas vezes desalinhadas: a primeira, 5 a 6 dentes mais desenvolvidos e a segunda, mais interna, 6 a 7 dentes menores; ambas complementamse para ocupar toda a margem ventral do pré-maxilar. Em jovens, os dentes são cônicos robustos com duas pequenas cúspides laterais; durante a ontogenia as cúspides são mantidas, mas os dentes tornam-se mamiliformes, especialmente aqueles situados na fileira externa. Dentário com dois dentes mamiliformes externos sem cúspides, um próximo à sínfise, dirigido para frente (= dente D4, LUCENA, 1998) e outro mais lateral, dirigido para frente e para fora (= dente D5, LuCENA, 1998). Em exemplares jovens (até $45 \mathrm{~mm} \mathrm{CP}$ ) distingue-se somente o dente $\mathrm{D} 5$, imediatamente à frente da fileira principal que, ao invés de estar dirigido para frente, está voltado para cima. A fileira principal de dentes do dentário é composta por um dente mamiliforme sinfiseano, seguido de 6 a 7 dentes cônicos robustos e um mamiliforme, todos com duas cúspides laterais muito pequenas; segue-se cerca de 8 a 12 dentes cônicos robustos; em exemplares adultos, são visualizadas duas pequenas cúspides laterais nos dois primeiros dentes.

Nadadeira dorsal, ii +9 raios, sua origem na vertical que passa pela origem da nadadeira anal ou logo atrás. Nadadeira peitoral, i+12-16 raios, seu raio mais longo ultrapassando levemente a origem da nadadeira anal. Margem póstero-inferior do cleitro com um entalhe desenvolvido formando uma projeção curta dirigida para trás e de extremidade arredondada; região ântero-inferior com uma projeção aguda conspícua dirigida para frente. Nadadeira ventral, i+7 raios; raio mais longo ultrapassa a origem da nadadeira anal, podendo alcançar, no máximo o oitavo raio desta nadadeira; machos com ganchos nas margens internas dos seis primeiros raios ramificados. Nadadeira anal, iv$\mathrm{v}+43-56$ raios, com uma bainha formada por 7 a 10 fileiras de escamas percorrendo toda sua base; machos com ganchos situados na margem posterior dos trinta e oito a quarenta primeiros raios. Nadadeira adiposa presente, sua origem situando-se entre as verticais que passam no $40^{\circ}$ ao $45^{\circ}$ raio ramificado da nadadeira anal. Nadadeira caudal, i+17+i raios principais com extremidade em forma de meia-lua. Vértebras pré-caudais 15 ou 16; caudais, 22 em 4 exemplares examinados.

Colorido em álcool. Coloração geral do corpo castanho-clara. Dorso escurecido. Mancha umeral escura, conspícua. Mancha no pedúnculo caudal presente, às vezes inconspícua, localizada à frente da base dos raios da nadadeira caudal. Uma faixa longitudinal escura desde a região superior da mancha umeral até a mancha do pedúnculo caudal; podendo estar difusa ou ausente. Em alguns exemplares, a região lateral do 
corpo, abaixo da faixa longitudinal escura, apresenta coloração prata que pode se estender à porção lateral da cabeça, atrás e sob a órbita. Todas as nadadeiras claras com esparsos cromatóforos escuros distribuídos sobre as membranas interradiais; cromatóforos mais concentrados nas nadadeiras dorsal e anal. Nadadeira peitoral com o raio indiviso e, geralmente, o primeiro raio ramificado, escuro. Nadadeira caudal com as extremidades dos raios escuros, contrastando com a coloração geral mais clara da nadadeira.

Distribuição. Bacias dos rios Paraguai, médio e baixo Paraná (fig. 6).

Comentários. LuCENA (1988: 34, fig. 5) comentou sobre a dificuldade de se estabelecer a localidade-tipo do holótipo de Roeboides microlepis, MHNG 8657-A, coletado por F. Castelnau e E. Deville. A análise com base nas poucas contagens e medidas indicava que o exemplar poderia ter sido capturado tanto na bacia Amazônica quanto na do rio Paraguai. Considerando essas alternativas, $R$. microlepis seria sinônimo sênior de $R$. myersii, espécie restrita à bacia Amazônica ou de $R$. bonariensis, restrita à bacia dos rios Paraguai e médio e baixo Paraná.

Com o exame de um maior número de exemplares procedentes de ambas drenagens, associado ao exame da radiografia do holótipo, restringiu-se a localidade-tipo de $R$. microlepis à bacia do rio Paraguai superior. Segundo Lucena (1988), quanto à baixa probabilidade do exemplar ter sido capturado no rio Araguaia, local mencionado no suporte de madeira onde se encontra preso o exemplar seco e onde a expedição de Castelnau coletou várias espécies de peixes (CASTELnAU, 1855), adiciona-se o fato de, até o momento, não terem sido capturados ou localizados em coleções científicas, espécimes do grupo microlepis provenientes do sistema Tocantins-Araguaia. Os levantamentos ictiofaunísticos feitos na região, especialmente provenientes da construção da UHE Serra da Mesa ou de projetos implementados pela Universidade do Tocantins (Paulo Lucinda, com. pess.), indicam que espécies do referido grupo não ocorram naquele sistema. Ao examinar a lista de localidades onde foram coletados peixes de água-doce (CAStelnau, 1855), verifica-se que, excluindo o sistema Tocantins-Araguaia, a grande maioria dos peixes foi capturada na bacia do rio Amazonas e no rio Ucayali. Em menor escala aparecem as localidades dos estados da Bahia, Rio de Janeiro e Minas Gerais. Roeboides microlepis (citada como Epycirtus gibbosus non Linnaeus, 1758, Valenciennes in Cuvier \& Valenciennes, 1850) e Hypostomus subcarinatus Castelnau, 1855 (Loricariidae) são as únicas espécies indicadas por CASTELNAU (1855) como tendo sido capturadas em “águas doces, ou rios, da província de Minas Gerais”. Veja Lucena (1988) para esclarecimentos quanto à improvável captura do exemplar-tipo nas drenagens dos rios São Francisco ou Paranaíba, sistemas que drenam o estado de Minas Gerais. O único momento em que Castelnau menciona o rio Paraguai como local de coleta (p. 68) é quando mencionou Myletes edulis Castelnau, 1855 (Serrasalminae citada como M. biddens Spix \& Agassiz, 1829). Ao referir-se ao exemplar dessa espécie, enviado ao Museu de Paris, Castelnau diz textualmente “cette espéce n'existait pas au Muséum de Paris avant que je l'eusse envoyée des rivieres centrales de l'Amérique du Sud". Mais abaixo, afirma que o exemplar foi capturado no rio Paraguai. Segundo PAPAVERO (1975), Castelnau após chegar a Cuiabá, estendeu sua viagem até o Paraguai, indo até Fuerte Olimpo (província de Olimpo), localidade fronteiriça com o Brasil situada às margens do rio Paraguai. Desde a saída de Castelnau de Cuiabá até seu retorno à Vila Maria (atual Cáceres), passam-se quase cinco meses. Nesse período foram feitas várias coletas e o material obtido foi 
deixado em Cáceres para ser enviado ao Rio de Janeiro e daí à Paris. Esse fato, associado ao que foi mencionado com relação a M. edulis, permite concluir que, embora a localidade "rio Paraguai" tenha sido citada uma única vez por Castelnau, ele realizou coletas naquele local e muito provavelmente em uma delas, o holótipo de $R$. microlepis tivesse sido coletado. Estes argumentos, e os apresentados por LUCENA (1988), parecem demonstrar que as localidades até o momento citadas como sendo do exemplar identificado como Epycyrtus gibbosus, "águas doces da província de Minas Gerais" por CASTELnAU (1855) e "rio Araguaia", mencionada no suporte de madeira onde está fixado o exemplar, estão ambas incorretas.

A análise de algumas contagens feitas em exemplares procedentes das bacias Amazônica e do rio Paraguai auxiliou a esclarecer em qual dessas bacias o exemplar pode ter sido capturado. Como foi dito anteriormente, o holótipo de $R$. microlepis é um exemplar seco. Assim sendo, qualquer medida ou contagem tomada do exemplar deve ser vista com cautela. De todas as medidas e contagens feitas nesse exemplar, somente a referente ao número de escamas perfuradas da linha lateral mostrou-se confiável e que foi de 106 escamas (110, em Valenciennes in CUVIER \& VALENCIENNES, 1850). Este valor o afasta do limite registrado para as populações da bacia Amazônica (no máximo 98 escamas) e se aproxima da população do rio Paraguai. Embora a população da bacia do rio Mamoré tenha média do número de escamas mais elevada em relação à população amazônica, os valores encontrados no holótipo ainda ficam deslocados dos limites da população do Mamoré. Adiciona-se a isso, o fato do exame dos arcos branquiais do holótipo, através de radiografias, ter mostrado, embora com difícil discriminação, que o número de rastros do ramo inferior do primeiro arco não ultrapassa 13, mantendo-se, dessa forma dentro dos limites observados para a população do rio Paraguai e afastando-o da população amazônica (fig. 5). Por fim, a presença de 56 raios ramificados na nadadeira anal do holótipo é valor próximo aos valores verificados na população do rio Paraguai.

Conclui-se que o holótipo de R. microlepis foi capturado no sistema do rio Paraguai e que nada havendo para diferenciá-lo da população de $R$. bonariensis descrita para o mesmo sistema, propõe-se que $R$. bonariensis seja considerada sinônimo júnior de $R$. microlepis, argüindo o Princípio da Prioridade (ICNZ, 1999: artigo 23).

\section{Roeboides myersii Gill, 1870}

(Figs. 5, 6, 9-13)

Roeboides myersii GiLl, 1870:92 (localidade-tipo: rios Maranhão e Napo, drenagem do Amazonas Superior).

Roeboides rubrivertex Cope, 1872:265 (localidade-tipo: entre a boca do rio Negro e o rio Ucayali, drenagem do Amazonas Superior e Médio).

Charax hasemani Steindachner, 1915:589 (localidade-tipo: foz do rio Negro, drenagem do médio Amazonas).

Material examinado. Holótipo, Roeboides rubrivertex, entre a boca do rio Negro e a amazônia peruana ou rio Ucayali, Robert Perkins col., ANSP 8190 (CP 112,7 mm). BRASIL, Acre: mercado de peixes de Sena Madureira, sistema do rio Purus, $09^{\circ} 9^{\prime} \mathrm{N}-69^{\circ} 35^{\prime} \mathrm{W}$, MCP 28821 (2, CP 134,3-135,8 $\mathrm{mm}$ ); igarapé Mapinguari, na estrada BR 364, $45 \mathrm{~km}$ a noroeste de Rio Branco, afluente do rio Andirá, MCP 28822 (1, CP 82,5 mm); cachoeira do Gastão, rio Juruá, MZSP 50452 (1, CP 101,6 $\mathrm{mm}$ ); foz do [rio] Breu, rio Juruá, MZSP 50453 (1, CP 124,0 mm); foz do [rio] Tejo, rio Juruá, MZSP 50454 (1, CP 118,0 mm). Amazonas: lago Castro, boca do rio Purus, MZSP 6287 (15, CP 64,2- 
129,8 mm); rio Madeira, $25 \mathrm{~km}$ baixo de Nova Olinda, MZSP 6967 (5, CP 79,7-117,9 mm; 1 exemplar, CP 90,9 mm, dc); lago Janauacá, rio Solimões, MZSP 20394 (3, CP 99,6-144,8 mm); Costa Japão, Ressaca do Japão, MZSP 27303 (1, CP 81,7 mm); paraná de Januacá, entrada do lago Castanho, MZSP não numerados (2, 40,0-55,0 mm CP, dc); Camaleão, ilha de Marchantaria, MZSP não numerado $(1,105,0 \mathrm{~mm} \mathrm{CP}, \mathrm{dc})$; próximo a boca do rio Embira, afluente do rio Tarauacá, drenagem do rio Juruá, $07^{\circ} 30^{\prime} \mathrm{S}-70^{\circ} 15^{\prime} \mathrm{W}$, USNM 94642 (1, CP 133,3 mm); Tabatinga [rio Solimões, $4^{\circ} 14^{\prime}$ 'S-69 $49^{\prime}$ 'W], USNM 119948 (7, CP 94,4-125,5 mm); [lago grande de] Manacapuru, [0306'S$61^{\circ} 30^{\prime} \mathrm{W}$ ], USNM 119950 (15, CP 82,1-141,2 $\mathrm{mm}$ ); [rio Tonantins] em Tonantins [junto ao rio Solimões, 02 ${ }^{\circ} 46^{\prime}$ S $-67^{\circ} 45^{\prime} \mathrm{W}$ ], USNM 119952 (15, CP 87,4-113,6 mm); Fonte Boa, [rio Solimões, 02³3'S-655' W], USNM 119953 (15, CP 93,3-133,6 mm); paraná do lago Janauacá, entrada do lago Castanho, próximo a Manaus, USNM 308585 (4, CP48,3-59,2 mm); lago Terra Preta, Janauari, USNM 309052 (2, CP 96,0-73,6 mm); ressaca da ilha de Marchantaria, rio Amazonas, USNM 309054 (5, CP 75,2-87,4 mm); lago Terra Preta, USNM 309055 (2, CP 84,1-91,9 mm); ilha de Marchantaria, Camaleão, USNM 309059 (1, CP 108,8 mm); igarapé entre Codajás e Coari, rio Solimões, próximo à boca do rio Paraná, USNM 311037 (1, CP 113,4 mm); igarapé na [estrada] Transamazônica, cerca de $5 \mathrm{~km}$ a oeste de Humaitá, sistema do rio Madeira, USNM 311044 (1, CP $58,6 \mathrm{~mm}$ ); rio Igarapé, próximo à confluência do rio Paraná com o rio Solimões, arredores de Tefé, USNM 311050 (1, CP 136,6 mm). Rondônia: rio Madeira, Calama, MZSP 34718 (227, sendo 13 examinados, CP 6,9-107,3 mm). Pará: rio Tapajós, Santarém, 02²6'S-54²4’ W, MCP 29305 (3, $\mathrm{CP} 73,0-144,6 \mathrm{~mm}$ ); rio Paituna, em frente à cidade de Monte Alegre, $02^{\circ} 0$ ' $0^{\prime \prime} \mathrm{S}-54^{\circ} 5^{\prime} 0^{\prime \prime} \mathrm{W}$, MCP 29303 (1, CP 72,3 mm); rio Amazonas, ilha São Miguel, rio Amazonas, 01 ${ }^{\circ} 56^{\prime}$ 'S-54 ${ }^{\circ} 44^{\prime} \mathrm{W}$, MZSP 20973 (1, CP 88,0 mm); rio Trombetas, $20 \mathrm{~km}$ acima da boca do rio, MZSP 38721 (3, CP 127,0144,7 mm). PERU, Loreto, rio Amazonas, resaca Poca Playa, M. Ramón Castilla, MUSM 6814 (4, CP 75,9-139,8 mm); Ucayali, rio Ucayali, Bagazan, Cel. Portillo, MZSP 26158 (3, CP 75,7-81,5 $\mathrm{mm}$ ); rio Ucayali, Ahanahao, Cel. Portillo, MZSP 26220 (7, CP 62,9-90,3 mm); rio Ucayali, Cel. Portillo, MZSP 26221 (4, CP 98,5-193,9 mm); rio Ampiyacu, USNM 124410 (4, CP 108,8-139,8 $\mathrm{mm})$. EQUADOR, Napo, laguna Limóncocha, drenagem do rio Napo, 0²3'4”S-76³7'1"W, MZSP 38677 (2, CP 57,4-62,9 mm). BOLIVIA, laguna San Luiz, rio Madre de Dios, cerca de $80 \mathrm{~km}$ acima de Ribeiralta, MZSP 35950 (1, CP 110,9 mm); Beni, rio Ibare, $5 \mathrm{~km}$ ao norte de Puerto Almacen, 144'0"'S-64'58'0"W, UF 82530 (10, CP 84,3-114,3 mm); rio Baures, afluente do rio Guaporé, bacia do rio Mamoré, 12³4'6”S-64¹9'W, UMMZ 204797 (6, CP 134,2-157,7 mm); rio Baures, 2 $\mathrm{km}$ acima da boca, afluente do rio Itenez, sistema do rio Madeira, $12^{\circ} 32^{\prime}$ 'S-64 $19^{\circ} 30^{\prime \prime} \mathrm{W}$, UMMZ 204873 (1, CP 130,5 mm); rio Itenez, $9 \mathrm{~km}$ a sudoeste de Costa Marques (Brasil), afluente do rio Mamoré, bacia do rio Madeira, 12³2’24”S-6412’42”W, UMMZ 204966 (1, CP 117,5 mm); Arroio Grande, $4 \mathrm{~km}$ a leste de Guayaramerin na estrada Riberalta, afluente do rio Mamoré, bacia do rio Madeira, 1049'30"S-65'26'42"W, UMMZ 205146 (1, CP 144,2 mm); rio Matos, afluente do rio

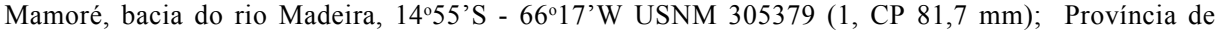
Ballivia, rio Matos, afluente do rio Mamoré, sistema do rio Madeira, $14^{\circ} 35^{\prime} \mathrm{S}-66^{\circ} 17^{\prime} \mathrm{W}$, USNM 305341 (4, CP 106,9-149,0 mm).

Diagnose. O conjunto de autapomorfias apresentado na análise filogenética distingue $R$. myersii das demais espécies do grupo-microlepis. Roeboides myersii distingue-se de $R$. margareteae, além dos caracteres da chave, pelo maior comprimento pré-ventral, 36,4\% a 42,2 \% do CP (média=38,6\%) contra 34,0\% a 37,4\% (média=35,8\%); menor comprimento da maxila, $50,3 \%$ a $63,7 \%$ (média $=56,4 \%$ ) do comprimento da cabeça, contra $60,2 \%$ a $65,1 \%$ (média $=62,0 \%$ ) e maior espaço interorbital, $25,3 \%$ a 32,0\% (média $=28,3 \%$ ) do comprimento da cabeça, contra $21,1 \%$ a 27,9\% (média=25,2\%). Das demais espécies do grupo-microlepis, $R$. myersii distingue-se de $R$. microlepis e $R$. araguaito pelo maior número total de rastros branquiais e número de rastros do ramo inferior do primeiro arco, respectivamente, 22 a 26 (média=23,8) e 14 a 16 (média=15,03) contra 19 a 23 (média=21,0) e 12 a 14 (média=13,2) naquelas espécies (fig. 5). Distinguese ainda de $R$. microlepis por apresentar o infraorbital 3 longo, alcançando a borda inferior do pré-opérculo, contra infraorbital 3 curto, não alcançando a borda inferior do 
pré-opérculo, em exemplares acima de $135 \mathrm{~mm} \mathrm{CP}$.

Descrição. Dados morfométricos e merísticos (tab. III). Corpo alto. Perfil dorsal formando uma gibosidade desde o terço posterior da órbita até a origem da nadadeira dorsal; a partir daí, reto e declinando abruptamente até o final da base dessa nadadeira, desse ponto continua reto e segue declinando suavemente, até o início do pedúnculo caudal onde, após sutil concavidade, eleva até a base dos raios superiores da nadadeira caudal. Perfil dorsal da cabeça reto ou levemente convexo sob o terço posterior da órbita até o final do focinho. Perfil ventral marcadamente convexo desde a ponta da mandíbula até a origem da nadadeira anal, reto a partir daí até o pedúnculo caudal (fig. 9). Pseudotímpano entre a primeira e a segunda costelas pleurais, algumas vezes não distinguível. Boca terminal. Maxilar longo, com 6 a 19 dentes, extremidade posterior entre as verticais que passam pela metade da órbita e sua margem posterior; jovens somente com dentes cônicos de base larga, e todos situados na margem ventral do osso; exemplares maiores de 51,0 mm CP com 5 a 8 dentes cônicos de base larga na margem ventral, seguidos de um ou dois dentes mamiliformes deslocados para a superfície externa, mais 4 a 9 dentes mamiliformes que reduzem-se em número, ontogeneticamente. Pré-maxilar com um dente mamiliforme dirigido para frente na sua superfície externa $(=$ dente D1, LUCENA, 1998), um dirigido para fora, localizado no ramo lateral (= dente D2, LuCENA, 1998) e um, menor entre ambos, dirigido para frente (= dente D3, LuCENA, 1998). Todos robustos e sem cúspides. Mais internamente os dentes não têm arranjo definido, diferindo inclusive entre os pré-maxilares direito e esquerdo. No arranjo mais comum, distinguemse duas fileiras de dentes: a primeira, 5 a 6 dentes mais desenvolvidos, geralmente desalinhada e com um ou mais dentes dirigidos para frente, e a segunda, mais interna, com 5 a 7 dentes menores; ambas complementam-se para ocupar toda a margem ventral do pré-maxilar. Em jovens, os dentes são cônicos robustos com duas pequenas cúspides laterais; durante a ontogenia as cúspides são mantidas embora pouco visíveis, ou ausentes, mas os dentes tornam-se mamiliformes. Dentário com dois dentes mamiliformes externos sem cúspides, um próximo à sínfise, dirigido para frente (= dente D4, LuCENA, 1998) e outro, mais lateral, dirigido para frente e para fora (=dente D5, LuCENA, 1998). Em exemplares jovens (até $48 \mathrm{~mm} \mathrm{CP}$ ), distingue-se somente o dente D5, dirigido para frente. A fileira principal de dentes do dentário é composta por um dente mamiliforme sinfiseano, seguido de 6 a 8 dentes cônicos robustos e um mamiliforme, todos com duas pequenas cúspides laterais que podem estar ausentes; segue-se cerca de 10 a 12 dentes cônicos robustos.

Nadadeira dorsal, ii +9 raios, sua origem na vertical que passa próximo, ou sobre, a origem na nadadeira anal. Nadadeira peitoral, i+12-16 raios, seu raio mais longo ultrapassando levemente a origem da nadadeira anal. Margem póstero-inferior do cleitro com um entalhe desenvolvido formando uma projeção curta dirigida para trás e de extremidade arredondada; região ântero-inferior com uma projeção aguda conspícua dirigida para frente. Nadadeira ventral, $\mathrm{i}+7$ raios; raio mais longo ultrapassa a origem da nadadeira anal, podendo alcançar, no máximo, o quinto raio desta nadadeira; machos com ganchos nas margens internas dos seis primeiros raios ramificados Nadadeira anal, iv-v+42-55 raios, com uma bainha formada por 7 a 10 fileiras de escamas percorrendo toda sua base; machos com ganchos situados na margem posterior dos trinta e cinco a quarenta primeiros raios. Nadadeira adiposa presente, sua origem situando-se entre as verticais que passam no $40^{\circ}$ ao $45^{\circ}$ raio ramificado da nadadeira anal. Nadadeira caudal, 
Tabela III. Medidas e contagens de Roeboides microlepis e R. myersii. Incluídas as medidas e contagens, aproximadas, do holótipo (MNHN A.8657) de R. microlepis (N, número de exemplares).

\begin{tabular}{|c|c|c|c|c|c|c|c|c|c|}
\hline & \multirow[b]{3}{*}{ Holótipo } & \multicolumn{4}{|c|}{ Roeboides microlepis } & \multirow[b]{3}{*}{$\mathrm{N}$} & \multicolumn{3}{|c|}{ Roeboides myersii } \\
\hline & & \multicolumn{3}{|c|}{ Limites } & \multirow[b]{2}{*}{ Média } & & \multicolumn{2}{|c|}{ Limites } & \multirow[b]{2}{*}{ Média } \\
\hline & & $\mathrm{N}$ & Inferior & Superior & & & Inferior & Superior & \\
\hline \multirow[t]{2}{*}{ Comprimento padrão (mm) } & 167 & 67 & 48,5 & 186,7 & 111,3 & 103 & 57,4 & 157,7 & 105,6 \\
\hline & \multicolumn{8}{|c|}{ Porcentagens do comprimento padrão } & \\
\hline Altura do corpo & 63,0 & 67 & 39,3 & 50,5 & 43,9 & 103 & 32,9 & 46,1 & 40,5 \\
\hline Comprimento pré-dorsal & 81,0 & 67 & 49,9 & 54,2 & 52,0 & 103 & 45,0 & 57,5 & 50,9 \\
\hline Comprimento pré-anal & 80,0 & 67 & 48,3 & 54,7 & 51,5 & 103 & 46,7 & 55,9 & 51,1 \\
\hline Comprimento pré-peitoral & - & 67 & 20,8 & 33,0 & 29,1 & 103 & 27,1 & 32,9 & 29,2 \\
\hline Comprimento pré-ventral & - & 67 & 35,8 & 42,0 & 39,2 & 102 & 36,4 & 42,2 & 38,6 \\
\hline Compr. pedúnculo caudal & - & 67 & 7,8 & 11,9 & 9,6 & 100 & 7,5 & 11,4 & 9,7 \\
\hline Altura pedúnculo caudal & - & 67 & 8,3 & 10,0 & 9,3 & 99 & 7,5 & 10,2 & 8,9 \\
\hline \multirow[t]{2}{*}{ Comprimento cabeça } & 43,0 & 67 & 25,0 & 31,6 & 28,1 & 102 & 25,5 & 31,8 & 28,3 \\
\hline & \multicolumn{9}{|c|}{ Porcentagens do comprimento da cabeça } \\
\hline Comprimento focinho & 8,0 & 67 & 19,2 & 27,6 & 24,5 & 101 & 21,5 & 29,6 & 25,0 \\
\hline Diâmetro órbita & 13,0 & 66 & 24,8 & 37,8 & 30,0 & 97 & 24,2 & 35,1 & 28,6 \\
\hline Comprimento maxila & - & 67 & 52,6 & 64,6 & 60,0 & 102 & 50,3 & 63,7 & 56,4 \\
\hline \multirow[t]{2}{*}{ Espaço inter-orbital } & - & 67 & 23,0 & 33,1 & 27,4 & 102 & 25,3 & 32,0 & 28,3 \\
\hline & \multicolumn{9}{|c|}{ Contagens } \\
\hline $\mathrm{N}^{\circ}$ raios nad. anal & 56 & 62 & 43 & 56 & 52,0 & 101 & 42,0 & 55,0 & 49,7 \\
\hline $\mathrm{N}^{\circ}$ raios nad. peitoral & 15 & 67 & 12 & 16 & 13,7 & 103 & 12,0 & 16,0 & 13,8 \\
\hline $\mathrm{N}^{\circ}$ rastros ramo inferior & - & 66 & 12 & 14 & 13,2 & 103 & 14,0 & 16,0 & 15,0 \\
\hline $\mathrm{N}^{\circ}$ rastros ramo superior & - & 63 & 6 & 9 & 7,8 & 102 & 8,0 & 10,0 & 8,8 \\
\hline $\mathrm{N}^{\circ}$ total rastros & - & 63 & 19 & 23 & 21,0 & 102 & 22,0 & 26,0 & 23,8 \\
\hline $\mathrm{N}^{\circ}$ esc. perf. linha lateral & 106 & 55 & 94 & 105 & 98,4 & 92 & 86,0 & 99,0 & 92,2 \\
\hline $\mathrm{N}^{\circ}$ esc. acima linha lateral & - & 50 & 27 & 32 & 29,0 & 85 & 22,0 & 30,0 & 25,6 \\
\hline $\mathrm{N}^{\circ}$ esc. abaixo linha lateral & 18 & 67 & 19 & 23 & 20,9 & 98 & 17,0 & 23,0 & 19,8 \\
\hline $\mathrm{N}^{\circ}$ esc. redor ped. caudal & - & 49 & 26 & 31 & 28,6 & 65 & 24,0 & 30,0 & 27,2 \\
\hline
\end{tabular}

$\mathrm{i}+17+\mathrm{i}$ raios principais com extremidade em forma de meia-lua. Vértebras pré-caudais 16 ; caudais 22, em 3 exemplares examinados.

Colorido em álcool. Coloração geral do corpo castanho-clara. Dorso escurecido. Mancha umeral escura, conspícua. Mancha no pedúnculo caudal presente, às vezes inconspícua, localizada à frente da base dos raios da nadadeira caudal. Uma faixa longitudinal escura desde a região superior da mancha umeral até a mancha do pedúnculo caudal, podendo se apresentar difusa ou ausente. Em alguns exemplares, a região lateral do corpo, abaixo da faixa longitudinal escura, apresenta coloração prata que pode se estender à porção lateral da cabeça, atrás e sob a órbita. Todas as nadadeiras claras com esparsos cromatóforos escuros distribuídos sobre as membranas interradiais; em alguns exemplares os cromatóforos estão mais concentrados em todas as nadadeiras dando a elas um aspecto escurecido. Nadadeira peitoral com o raio indiviso e os primeiros raios ramificados, escuros. O mesmo padrão ocorre na nadadeira ventral.

Distribuição. Amplamente distribuída na bacia Amazônica, exceto nas drenagens do escudo das Guianas e nos rios Tapajós, Xingu e sistema Tocantins-Araguaia (fig. 6). Variação populacional. No material examinado, dois exemplares (MZSP 38721) do 


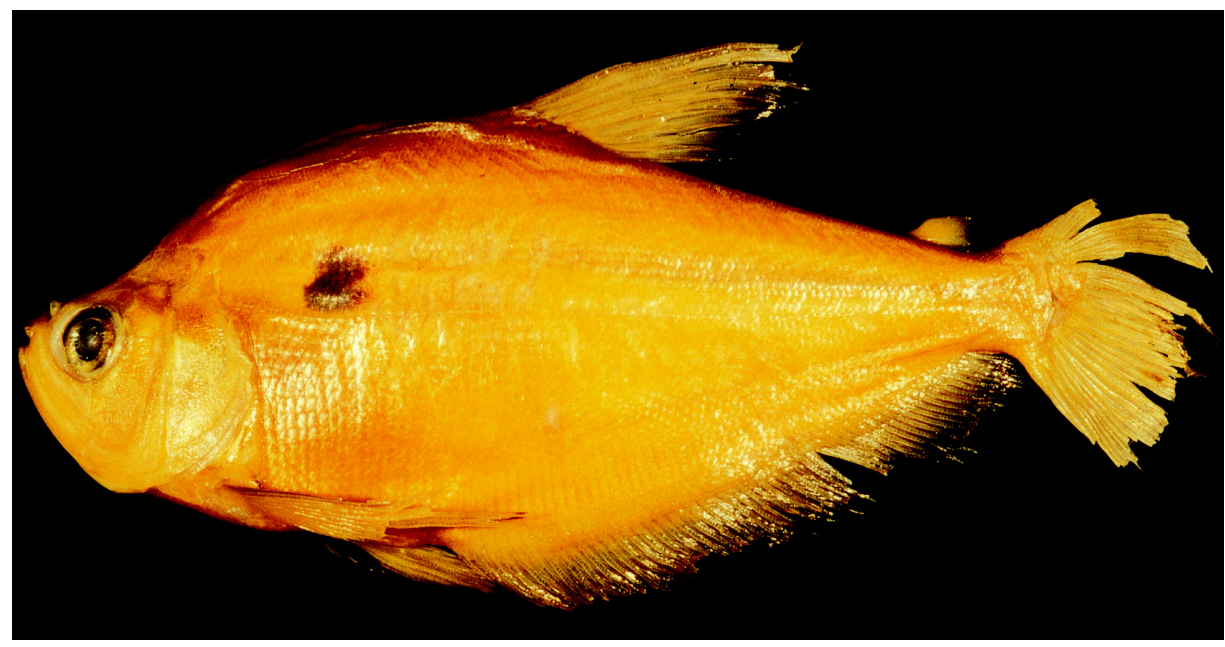

Fig. 10. Roeboides myersii, ANSP 204797, rio Baures, bacia do rio Mamoré, Bolívia, 141,7 mm CP.

rio Trombetas, apresentam o olho comparativamente maior do que o restante da população, exceto quando comparados com alguns exemplares da drenagem do rio Mamoré, bacia do rio Madeira superior. A população do rio Mamoré (fig. 10) por sua vez, em relação ao restante da população, mostrou variação para maior do número de escamas perfuradas da linha lateral e escamas acima da linha lateral (figs. 11, 12). Mostrou também, quando comparados exemplares acima de $135 \mathrm{~mm}$ de $\mathrm{CP}$, maior altura do corpo em relação ao comprimento padrão (fig. 13).

\section{DISCUSSÃO}

As quatro espécies representantes do grupo-microlepis ocorrem em drenagens distintas da porção cis-andina da América do Sul, possuindo portanto, distribuições caracteristicamente alopátricas. De leste para oeste, Roeboides margareteae ocorre no sistema Pindaré-Mearim e na bacia do rio Parnaíba, porção oeste da região nordeste do Brasil; $R$. microlepis distribui-se na bacia do rio Paraguai e médio e baixo rio Paraná; $R$. myersii ocupa o rio Amazonas/Solimões e seus afluentes da margem direita, com exceção daqueles situados mais a leste, Tapajós e Xingú e sistema Tocantins-Araguaia; $R$. araguaito ocupa a bacia do rio Orinoco e alguns afluentes da margem direita (fig. 6).

Associando a distribuição acima descrita à hipótese de relações proposta no presente trabalho (fig. 1), obtém-se um cladograma de área (fig. 14) a partir do qual algumas inferências podem ser feitas. Dois clados irmãos são identificados: 1) abrangendo a porção leste da América do Sul com as espécies $R$. microlepis e $R$. margareteae e 2) representando a porção oeste, com $R$. myersii e $R$. araguaito. São escassas as revisões feitas com táxons de distribuição semelhante a do grupo-microlepis e que incluam análises filogenéticas. Um dos exemplos registrados, diz respeito a revisão do gênero 

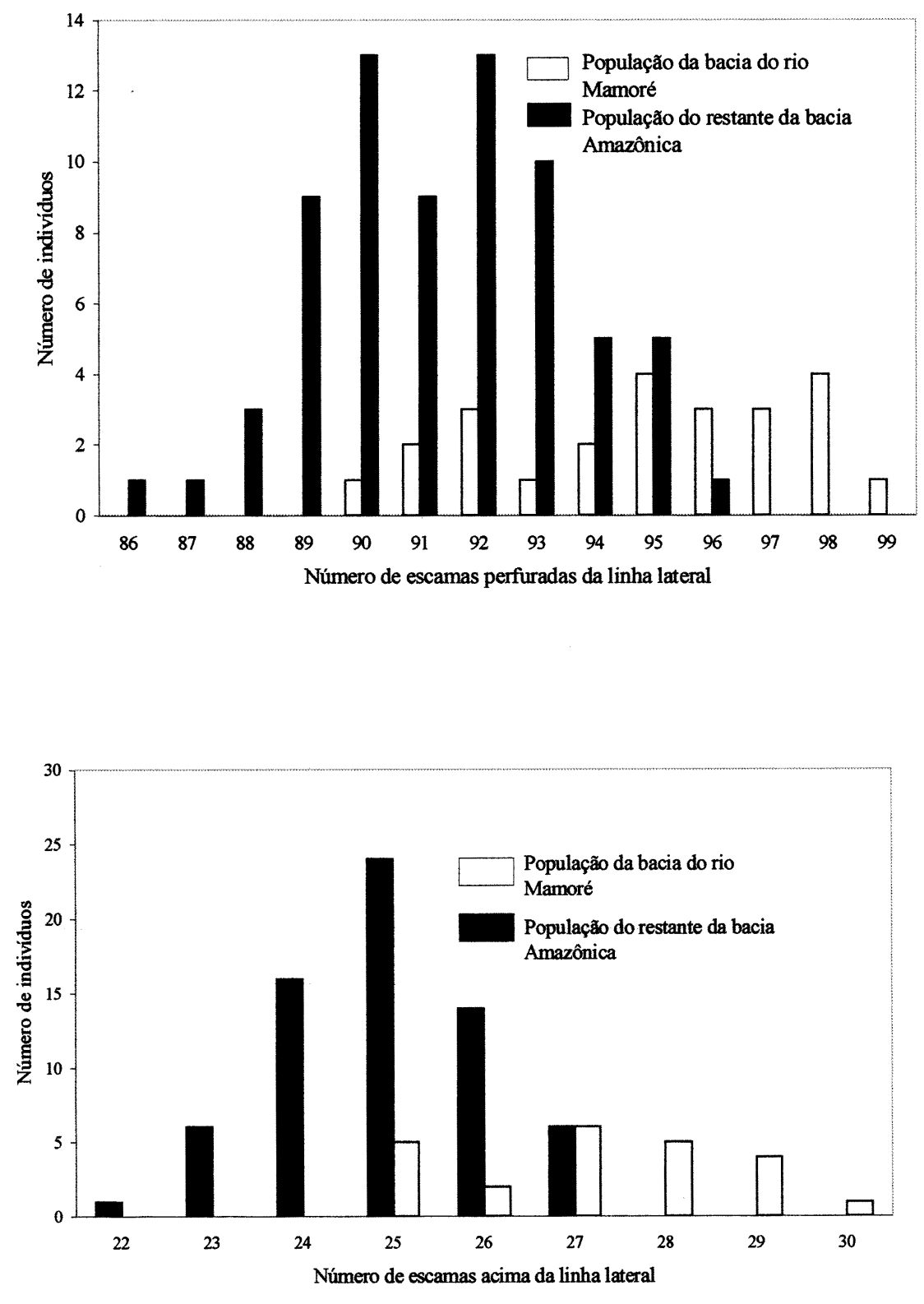

Figs. 11, 12. Distribuição da freqüência do número de escamas da linha lateral em Roeboides myersii, considerando as populações da bacia do rio Mamoré e do restante da bacia Amazônica. 11, escamas perfuradas da linha lateral; 12, escamas acima da linha lateral. 

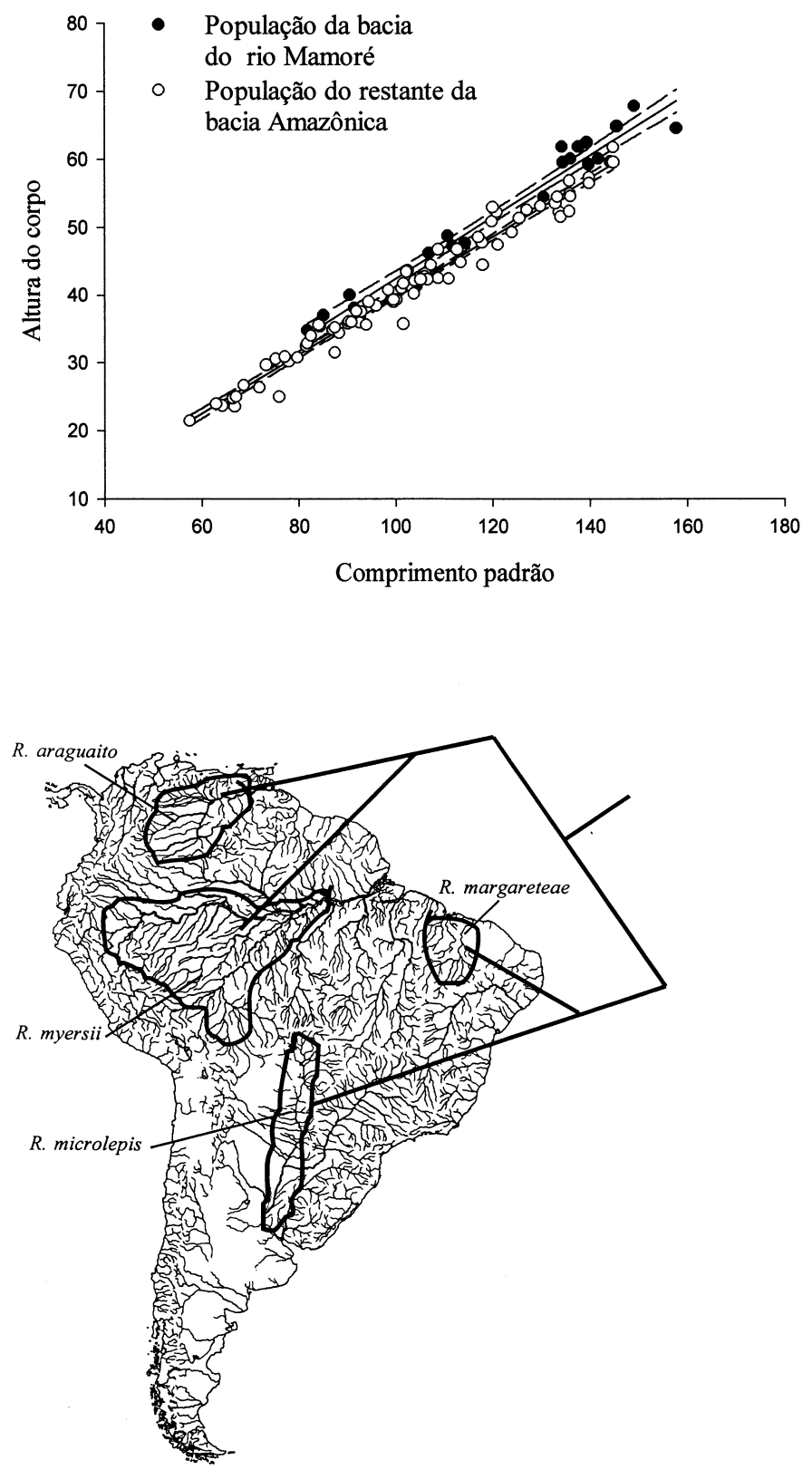

Figs. 13, 14. 13, Relação entre a altura do corpo e o comprimento padrão em Roeboides myersii, considerando as populações da bacia do rio Mamoré e do restante da bacia Amazônica (linha tracejada corresponde aos limites de confiança de 95\%); 14, mapa da América do Sul superposto pelo cladograma das relações interespecíficas de Roeboides grupo-microlepis. 
Psectrogaster Eigenmann \& Eigenmann, 1889. Nela a espécie P. saguiru (Fowler, 1941) (Curimatidae) do nordeste do Brasil, é proposta como mais relacionada à $P$. rutiloides (Kner, 1858) da bacia Amazônica (VARI,1989) e P. rhomboides Eigenmann \& Eigenmann, 1889 do nordeste do Brasil faz parte de uma tricotomia com P. amazonica Eigenmann \& Eigenmann, 1889 da bacia Amazônica e P. curviventris Eigemnann \& Kennedy, 1903 do rio Paraguai e porções meridionais do sistema do rio Madeira (VARI, 1988; 1989). Independentemente das alternativas de relações para esta última espécie, esses resultados obtidos em Curimatidae demonstram uma tendência que aponta maior afinidade entre as espécies do nordeste do Brasil e a da bacia Amazônica, ao contrário do que foi encontrado aqui para o grupo-microlepis.

Interessante observar que o primeiro evento cladogênico ocorrido no grupomicrolepis corrobora a disjunção das áreas propostas por AMORIM \& PIREs (1996, fig. 25), respectivamente, componentes sudeste e noroeste, para a Região Neotropical. O autor associa eventos de transgressões marinhas e cobertura fluvial ocorridas no Cretáceo tardio (aproximadamente $100 \mathrm{Ma}$ ) para explicar tal efeito vicariante. Mesmo que a hipótese de AMORIm \& Pires (1996) seja para ambientes de florestas, portanto, aplicável a grupos de animais terrestres, a semelhança encontrada pode indicar que a história do grupomicrolepis esteja relacionada a tais eventos vicariantes.

Agradecimentos. A R. P. Vari e S. Jewet (USNM) pelo empréstimo de material e informações sobre o material da Expedição Thayer depositada naquela instituição; M. L. Bauchot pelo empréstimo do holótipo de R. microlepis quando curadora da coleção (1977) e a M. Jegú e R. Causse pela radiografia e dados merísticos adicionais do mesmo exemplar enviados em 2001 (MNHN). Pelo empréstimo de exemplares: K. Hartel (MCZ); F. Provenzano (MUCV); J. Lundberg \& M. Sabaj (ANSP); D. Nelson (UMMZ); O. Oiakawa (MZSP); S. Kullander e E. Ahlander (NRM). À Heraldo Britski pelo envio de foto e dados biométricos do material coletado no nordeste do Brasil. Vinicius Bertaco (MCP) preparou o material utilizado para osteologia e E. H. Pereira (MCP) realizou as fotos. Dois revisores anônimos deram valiosas sugestões ao manuscrito.

\section{REFERÊNCIAS BIBLIOGRÁFICAS}

Amorim, D. de S. \& Pires, M. R. 1996. Neotropical biogeography and a method for maximum biodiversity estimation. In: BICUdo, C. E. DE M. \& Menezes, N. A. eds. Biodiversity in Brazil. A first approach. São Paulo, Conselho Nacional de Desenvolvimento Científico e Tecnológico. p.183-219.

Castelnau, F. 1855. Poissons. In: Animaux nouveaux or rares recueillis pendant l'expédition dans les parties centrales de l'Amérique du Sud, de Rio de Janeiro a Lima, et de Lima au Para; exécutée par ordre du gouvernement Français pendant les années 1843 a 1847. Paris, Bertrand. 112p.

Cope, E. D. 1872. On the fishes of the Ambyiacu River. Proc. Acad. nat. Sci. Philad., Philadelphia, 23:250-294.

Cuvier, G. \& Valenciennes, A. 1850. Histoire naturelle des poissons. Paris, Strasbourg. 532p.

Dingerkus, G. \& Uhler, L. 1977. Enzyme clearing alcian blue stained whole vertebrates for demostration of cartilage. Stain Technol., Maryland, 52:229-232.

Eigenmann, C. H. 1910. Catalogue of the fresh-water fishes of tropical and south temperate America. Reports of the Princeton University expeditions to Patagonia 1896-1899, Zool. 3(4):375511.

Fink, W. L. \& Weitzman, S. H. 1974. The so-called cheirodontin fishes of Central America with descriptions of two new species (Pisces: Characidae). Smithson. Contr. Zool., Washington, 172:1-46.

Forey, P. L.; Humphries, C. J. et. al. 1992. Cladistics. A practical course in sytematics. Oxford, Claredon. 191p. (The Systematics Association Publication $\mathrm{n}^{\circ} .10$ ). 
Gill, T. N. 1870. On some new species of fishes obtained by Prof. Orton from the Maranon, or Upper Amazon, and Napo Rivers. Proc. Acad. nat. Sci. Philad., Philadelphia, 22:92-96.

Hennig, W. 1966. Phylogenetic Systematics. Urbana, University of Illinois. 203p.

ICZN. 1999. International Code of Zoological Nomenclature. 4. ed. London, International Comission on Zoological Nomenclature. 306p.

Lucena, C. A. S. 1987. Revisão e redefinição do gênero neotropical Charax Scopoli, 1777 com a descrição de quatro espécies novas (Pisces; Characiformes; Characidae). Com. Mus. Ciênc. PUCRS, Porto Alegre, (40):4-124.

1988. Lista comentada das espécies do gênero Roeboides Günther, 1864 descritas para as bacias dos rios Amazonas, São Francisco e da Prata (Characiformes, Characidae, Characinae). Comun. Mus. Ciênc. PUCRS, Sér. Zool., Porto Alegre, 1(3):29-47.

1998. Relações filogenéticas e definição do gênero Roeboides Günther (Ostariophysi: Characiformes: Characidae). Comun. Mus. Ciênc. Tecnol. PUCRS, Sér. Zool., Porto Alegre, 11:19-59.

2000a. Revisão taxonômica e filogenia das espécies transandinas do gênero Roeboides Günther (Teleostei: Ostariophysi: Characiformes). Comun. Mus. Ciênc. Tecnol. PUCRS, Sér. Zool., Porto Alegre, 13:3-63.

2000b. Duas novas espécies do gênero Roeboides Günther das bacias dos rios Orinoco e

Amazonas (Teleostei, Characiformes, Characidae). Biociências, Porto Alegre, 8(2):153-162.

2001. Uma nova espécie de Roeboides Günther da região superior da bacia Amazônica

(Teleostei: Characiformes: Characidae). Biotemas, Florianópolis, 14(2):61-70.

Lucena, C. A. S. \& Menezes, N. A. 1998. A phylogenetic analysis of Roestes Günther and Gilbertolus Eigenmann, with a hypothesis on the relationships of the Cynodontidae and Acestrorhynchidae (Teleostei: Ostariophysi: Characiformes). In: Malabarba, L. R.; Reis, R. E. et al. eds. Phylogeny and Classification of Neotropical Fishes. Porto Alegre, Edipucrs. p. 261-278.

Maddison, W. P.; Donaghue, M. J. \& Maddison, D. R. 1984. Outgroup analysis and parsimony. Syst. Zool., Philadelphia, 33:83-103.

Menezes, N. A \& Lucena, C. A. S. 1998. Revision of the family Roestinae (Ostariophysi: Characiformes: Cynodontidae). Ichthyol. Explor. Freshwaters, Munchen, 9(3):279-291.

Papavero, N. 1975. Essays on the history of neotropical dipterology. São Paulo, Museu de Zoologia. v. 1, 216p.

RAE, T. C. 1998. The logical basis for the use of continuous characters in phylogenetic systematics. Cladistics, San Diego, 14:221-228.

Reinhardt, J. T. 1851. Nye sydamerikanske Ferskvandsfiske. Vidensk. Meddr. dansk naturh. Foren., Copenhague, 1849(3-5):29-57.

Steindachner, F. 1879. Über einige neue und seltene Fischarten aus den Zoologischen Museen zu Wien, Stuttgart und Warschau. Anz. Akad. Wiss. Wien, Wien, 16(4):29-34.

1915. Ichthyologische Beiträge (XVIII). Anz. Akad. Wiss. Wien, Wien, 52(27):346-349.

VARI, R. P. 1988. The Curimatidae, a lowland neotropical fish family (Pisces: Characiformes); distribution, endemism, and phylogenetic biogeography. In: Workshop on Neotropical Distribution Patterns, $1^{\circ}$, Rio de Janeiro, 1987, Proceedings..., Rio de Janeiro, Academia Brasileira de Ciências. p.343-377.

1989. Systematics of the neotropical characiform genus Psectrogaster Eigenmann \& Eigenmann (Pisces, Characiformes). Smithson. Contr. Zool., Washington, 481:1-43.

Weitzman, S. H. 1962. The Osteology of Brycon meeki, a generalized characid fish, with an osteological definition of the family. Stanford Ichthyol. Bull., Stanford, 8(1):3-77.

Weitzman, S. H. \& Malabarba, L. R. 1999. Systematics of Spintherobolus (Telesotei: Characidae: Cheirodontinae). Ichthyol. Explor. Freshwaters, München, 10(1):1-43.

Wiley, E. O. 1981. Phylogenetic: The Theory and Practice of Phylogenetic Systematics. New York, John Wiley \& Sons. 439p.

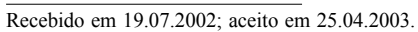

